\title{
Early goal-directed therapy in severe sepsis and septic shock: insights and comparisons to ProCESS, ProMISe, and ARISE
}

H. Bryant Nguyen ${ }^{1,2}$, Anja Kathrin Jaehne ${ }^{3,22}$, Namita Jayaprakash ${ }^{4}$, Matthew W. Semler $^{5}$, Sara Hegab ${ }^{6}$, Angel Coz Yataco ${ }^{7}$, Geneva Tatem ${ }^{6}$, Dhafer Salem ${ }^{8}$, Steven Moore ${ }^{3}$, Kamran Boka ${ }^{9}$, Jasreen Kaur Gill ${ }^{3}$, Jayna Gardner-Gray 3,6, Jacqueline Pflaum, ${ }^{3,6}$, Juan Pablo Domecq ${ }^{10,11}$, Gina Hurst ${ }^{3,6}$, Justin B. Belsky ${ }^{12}$, Raymond Fowkes ${ }^{3}$, Ronald B. Elkin ${ }^{13}$, Steven Q. Simpson ${ }^{14}$, Jay L. Falk ${ }^{15,16,17,18,19}$, Daniel J. Singer ${ }^{20}$ and Emanuel P. Rivers ${ }^{3,21^{*}}$

\begin{abstract}
Prior to 2001 there was no standard for early management of severe sepsis and septic shock in the emergency department. In the presence of standard or usual care, the prevailing mortality was over 40-50\%. In response, a systems-based approach, similar to that in acute myocardial infarction, stroke and trauma, called early goal-directed therapy was compared to standard care and this clinical trial resulted in a significant mortality reduction. Since the publication of that trial, similar outcome benefits have been reported in over 70 observational and randomized controlled studies comprising over 70,000 patients. As a result, early goal-directed therapy was largely incorporated into the first 6 hours of sepsis management (resuscitation bundle) adopted by the Surviving Sepsis Campaign and disseminated internationally as the standard of care for early sepsis management. Recently a trio of trials (ProCESS, ARISE, and ProMISe), while reporting an all-time low sepsis mortality, question the continued need for all of the elements of early goal-directed therapy or the need for protocolized care for patients with severe and septic shock. A review of the early hemodynamic pathogenesis, historical development, and definition of early goal-directed therapy, comparing trial conduction methodology and the changing landscape of sepsis mortality, are essential for an appropriate interpretation of these trials and their conclusions.
\end{abstract}

\section{Background}

The early physiologic-hemodynamic response to severe sepsis and septic shock

In animal and human models of early sepsis, global tissue hypoxia results from hemodynamic perturbations that create an imbalance between systemic oxygen delivery and demands. These perturbations can include hypovolemia, decreased vasomotor tone, decreased arterial oxygen content, myocardial depression, increased metabolic demands, and impairment of systemic oxygen utilization via microcirculatory or mitochondrial

\footnotetext{
* Correspondence: erivers1@hfhs.org

${ }^{3}$ Department of Emergency Medicine, Henry Ford Hospital, Wayne State University, Detroit, MI, USA

${ }^{21}$ Department of Surgery, Henry Ford Hospital, Wayne State University, Detroit, MI, USA

Full list of author information is available at the end of the article
}

derangements (cytopathic tissue hypoxia) [1]. A critical decrease in systemic oxygen delivery is followed by an increase in the systemic oxygen extraction ratio and a decrease in mixed or central venous $\left(\mathrm{SvO}_{2}\right.$ or $\left.\mathrm{ScvO}_{2}\right)$ oxygen saturation. Anaerobic metabolism ensues when the limits of this compensatory mechanism cannot maintain systemic oxygen consumption leading to lactate production [2]. The final, and often terminal, stage is an impairment of systemic oxygen utilization. Patients in this stage have elevated $\mathrm{ScvO}_{2}$, increased lactate, and decreased systemic oxygen consumption (Additional file 1: Figure S1).

As a result of this early response, distinct hemodynamic phenotypes emerge. Characterizing patients by distinct hemodynamic phenotypes using $\mathrm{ScvO}_{2}$, lactate, and blood pressure provides diagnostic, therapeutic, and prognostic staging of sepsis for study 
comparisons. These hemodynamic phenotypes reflect distinct stages along a continuum of disease whether pre-hospital, in the emergency department (ED), on general practice floors or in the intensive care unit (ICU) setting.

\section{The history and development of early goal-directed ther- apy (EGDT)}

Beginning in the early 1990s, the EGDT Collaborative Group challenged the paradigm of sepsis care as an "ICU disease" by applying similar urgent diagnostic and therapeutic principles as used for acute myocardial infarction, stroke, and trauma at the point of presentation in the ED. At that time, no structured formal worldwide accepted protocols for early identification and treatment of patients with sepsis existed. The observations of high mortality, fractured, and unstructured care triggered a series of investigations using a system-based approach to identify delays in patient diagnosis and care before hospital admission. Combining system issues with the early pathogenesis and natural progression of sepsis required the development of unique diagnostic and risk stratification criteria to detect patients at risk and most likely to benefit (Fig. 1) [3].

\section{From EGDT to ProCESS, ARISE and ProMISe}

EGDT is comprised of early identification of high-risk patients, appropriate cultures, source control, and administration of appropriate antibiotics. This is followed by early hemodynamic optimization of oxygen delivery, guided by preload (central venous pressure (CVP) or surrogate targeting with fluids), afterload (mean arterial pressure (MAP) targeted with vasopressors), arterial oxygen content (packed red blood cells and/or oxygen supplementation), contractility (inotropic agents), and decreasing oxygen consumption (mechanical ventilation and sedation), and guided by $\mathrm{ScvO}_{2}$. These principles were essentially best practice recommendations for sepsis management in the ICU setting (Fig. 1) [4].

After observing a local hospital mortality of over $50 \%$ for severe sepsis and septic shock, an institutional quality improvement initiative led to the randomized controlled trial of EGDT between 1997 and 2000 [3]. After validity, reliability, and feasibility testing across multiple healthcare settings both nationally and internationally for over a decade, EGDT became part of the fundamental components of the sepsis resuscitation bundle for the Surviving Sepsis Campaign (SSC), the National Quality Forum and Centers for Medicare and Medicaid Services [5].

Since the EGDT publication, significant scientific interest was generated to "disassemble or unbundle" early sepsis resuscitation and question the value of its individual components [6,7]. Even though EGDT was based on a series of investigations to systematically improve sepsis outcomes, it has been inappropriately characterized as a hemodynamic optimization study driven by CVP and $\mathrm{ScvO}_{2}$ as targets for early shock resolution [8-11]. There was also the additional question of its external validity because it was a single center study with an "unusually high" control group mortality of $46.5 \%$. Recently, a "trio of trials" which examined versions of EGDT called ProCESS (Protocol-Based Care for Early Septic Shock), ARISE (Australasian Resuscitation in Sepsis Evaluation) and ProMISe (Protocolized Management in Sepsis) were published from a related consortium of investigators [12-14].

The trio of trials of EGDT reported an unprecedented all-time low in sepsis mortality for all treatment groups compared to historical controls (Table 1). However, they concluded: "EGDT does not show improved survival for patients randomized to receive EGDT compared to usual care or to less invasive alternative hemodynamic resuscitation protocols. EGDT is, however, associated with increased admission to ICU. Our findings do not support the systematic use of EGDT in the management of all patients with septic shock or its inclusion in the Surviving Sepsis Campaign guidelines" [15]. The purpose of this review is to provide the reader with the critical information needed to objectively interpret the purpose, methodology, results, and conclusion of the trio of EGDT trials [16-19].

\section{Review}

\section{Enrollment procedures and logistics}

The location, number of centers, hospital setting and size, and number of ED visits for the EGDT and trio of EGDT trials are noted in Table 2 and Additional file 1, Table S1. Trials were primarily conducted in academic/tertiary care centers, where higher patient volumes are associated with better outcomes [20]. The trio of EGDT trials began 8 years after completion of the EGDT trial, were conducted over a 5-year period, and published more than 14 years after the EGDT trial. This time period also paralleled the introduction (2004) and two revisions of the SSC guidelines in 2008 and 2013 [5].

Eligible patients were excluded in $10.4 \%, 65 \%, 42.7 \%$, and $55.4 \%$ of the EGDT, ProCESS, ARISE, and ProMISe trials, respectively. The enrollment rate was 7 patients per month for the EGDT trial compared with 0.5 to 0.7 patients per month per center in the trio of EGDT trials (Table 2). Daytime and weekday enrollment (as in the ProMISe trial) is associated with lower mortality when compared to nighttime and weekends [21, 22]. High exclusion rates, convenient enrollment, low patient per site relative to high-volume recruitment, and a 5-year duration of enrollment methodologically challenges the external validity of even large randomized trials [19]. 


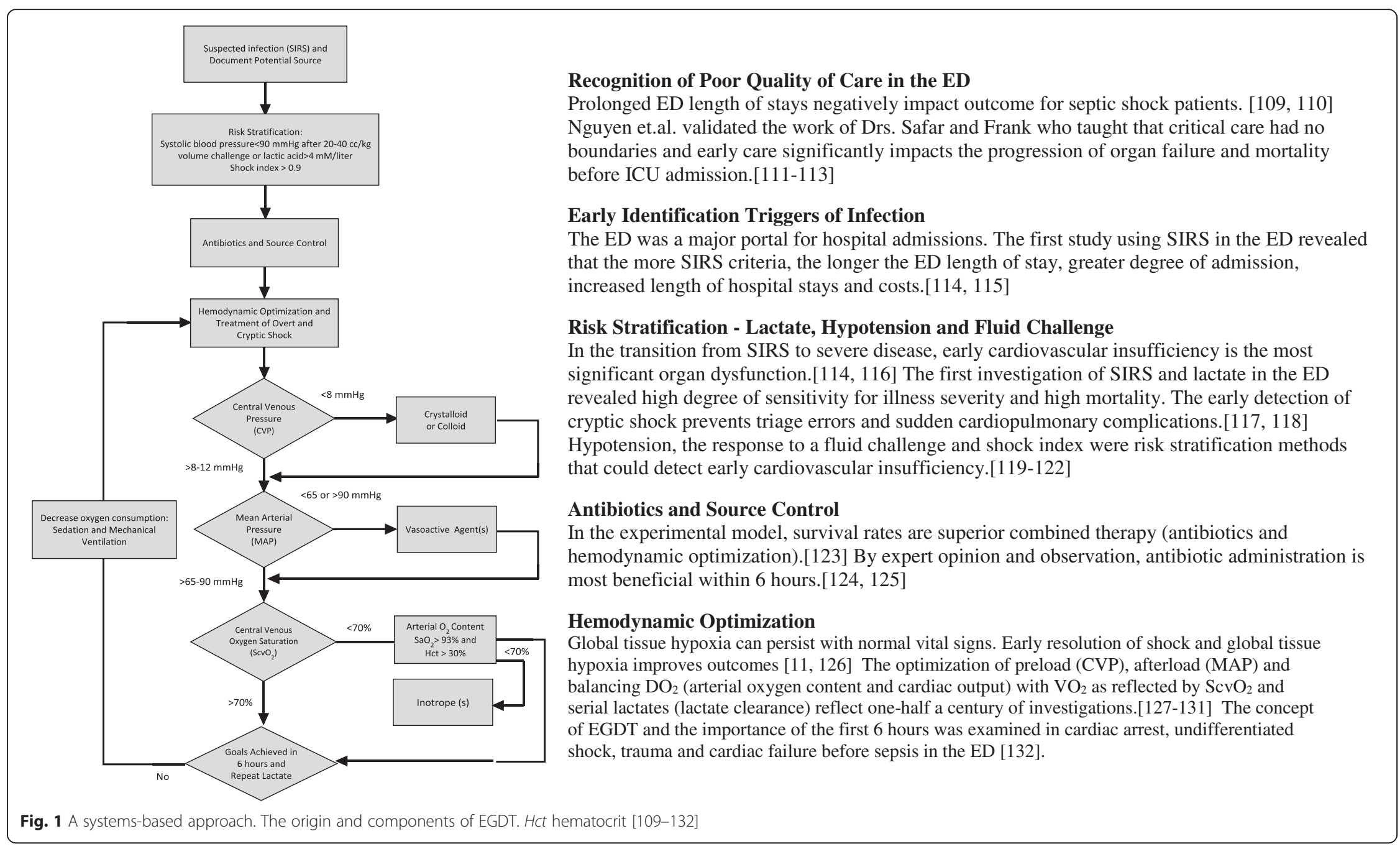


Table 1 Comparison of observational studies before and during the EGDT, ProCESS, ProMISe and ARISE trials

\begin{tabular}{|c|c|c|c|}
\hline Studies & Year & Mortality before $(\%)^{a}$ & Mortality after $(\%)^{b}$ \\
\hline EGDT [3] & 1997-2000 & 46.5 & 30.5 \\
\hline Shanker-Hari et al. (septic shock) [96] $(n=52, n=166,479)$ & 1993-2015 & 46.5 & $\mathrm{n} / \mathrm{a}$ \\
\hline \multicolumn{4}{|l|}{ US observational Studies } \\
\hline Dombrovsky et al. (severe sepsis) [133] & 2001 & 40.3 & $\mathrm{n} / \mathrm{a}$ \\
\hline Ani et al. (severe sepsis) [134] & 1999-2008 & 40.0 & 27.8 \\
\hline Stevenson et al. [135] & 1993-2009 & 46.9 & 29.2 \\
\hline Kumar et al. (severe sepsis) [136] & 2003-2009 & 39.6 & 27.3 \\
\hline Kumar et al. (septic shock) [136] & $2000-2007$ & 47.1 & 36.4 \\
\hline Mechanically ventilated patients [60] & 2002-2012 & 64.1 & 39.7 \\
\hline \multicolumn{4}{|l|}{ Studies of EGDT (number of studies, number of patients) } \\
\hline Quasi experimental studies $(n=4, n=1120)$ [137-140] & $2001-2016$ & 45.8 & 28.5 \\
\hline Prospective observational $(n=38, n=66,862)[43,87,91,93,94,141-174]$ & $2001-2016$ & 40.3 & 27.6 \\
\hline Prospective with historical controls $(n=9, n=2250$ ) [175-183] & $2001-2016$ & 45.5 & 29.6 \\
\hline Retrospective $(n=10, n=2183)$ [184-193] & $2001-2016$ & 41.1 & 24.7 \\
\hline Randomized control trials $(n=11, n=5756)[3,12-14,79,194-199]$ & $2001-2016$ & 31.3 & 26.2 \\
\hline ProCESS [12] & 2008-2013 & 18.9 & $19-20$ \\
\hline \multicolumn{4}{|l|}{ United Kingdom observational studies } \\
\hline Padkin et al. [200] & 1995-2000 & 47.0 & $\mathrm{n} / \mathrm{a}$ \\
\hline Gao et al. [148] & 2004-2005 & 55.0 & 29.0 \\
\hline Reuben et al. [201] & 2004-2005 & 43.0 & $\mathrm{n} / \mathrm{a}$ \\
\hline Melville et al. [202] & $2005-2008$ & 51.9 & 41.3 \\
\hline Daniels et al. [203] & $2007-2008$ & 44.1 & 20.0 \\
\hline Sivayoham et al. [189] & $2006-2009$ & 42.8 & 22.7 \\
\hline ProMISe [14] & $2011-2014$ & 25.6 & 24.6 \\
\hline \multicolumn{4}{|l|}{ Australia and New Zealand observational studies } \\
\hline Finfer et al. (severe sepsis) [204] & 1999 & 37.5 & $\mathrm{n} / \mathrm{a}$ \\
\hline Kaukonen et al. (severe sepsis, with co morbidities) [205] & $2000-2012$ & 46.3 & 23.4 \\
\hline Kaukonen et al. (severe sepsis) [205] & $2000-2012$ & 30.2 & 14.2 \\
\hline Kaukonen et al. (septic shock) [205] & 2000-2012 & 40.3 & 22.0 \\
\hline ARISE [13] & 2008-2014 & 18.8 & 18.6 \\
\hline
\end{tabular}

aefore (baseline, usual or control); ${ }^{\mathrm{b}}$ After (treatment). References are given in Additional file 1 (Table S6)

ARISE Australasian Resuscitation in Sepsis Evaluation, EGDT Early Goal-Directed Therapy, ProCESS Protocolized Care for Early Septic Shock, ProMISe Protocolized Management in Sepsis

\section{Baseline enrollment criteria (SIRS, lactate, and blood pressure)}

An increased respiratory rate, lower partial pressure of carbon dioxide, and decreased temperature were the more prominent systemic inflammatory response syndrome (SIRS) criteria in the EGDT study patients. Additionally, the EGDT study patients had a greater degree of metabolic acidosis and lower $\mathrm{ScvO}_{2}$, reflecting greater shock severity (Table 3) [23-25]. While lactate remains an excellent early screening tool, the incidence of a normal lactate level in septic shock is frequent, necessitating an alternative method of risk stratification such as hypotension [26, 27]. On the other hand, intermediate lactate levels $(2-4 \mathrm{mM} / \mathrm{L})$ are also associated with increased mortality which is significantly reduced (19\% odds ratio for hospital mortality) with protocolized care [28-32].

A hypotensive episode is associated with an increased risk of death and the response to an adequate fluid challenge improves upon this discriminatory value [32, 33]. The fluid challenge requirement of EGDT $(20-30 \mathrm{~mL} / \mathrm{kg})$ after randomization into the study was significantly higher than the 1 liter fixed bolus over $60 \mathrm{~min}$ prior to randomization used in the trio of EGDT trials (Table 4, Additional file 1: Figure S3 ). Patients enrolled in these trials because they remained hypotensive after 1 liter of crystalloid may not 
Table 2 Enrollment characteristics and data

\begin{tabular}{|c|c|c|c|c|c|c|c|c|c|}
\hline \multirow[b]{2}{*}{ Treatment groups } & \multicolumn{2}{|c|}{ EGDT } & \multicolumn{3}{|c|}{ ProCESS } & \multicolumn{2}{|c|}{ ARISE } & \multicolumn{2}{|c|}{ ProMISe } \\
\hline & EGDT & Control & EGDT & PBST & Usual & EGDT & Control & EGDT & Usual \\
\hline Location & \multicolumn{2}{|c|}{ United States } & \multicolumn{3}{|c|}{ United States } & \multicolumn{2}{|c|}{ Multinational $^{a}$} & \multicolumn{2}{|c|}{ United Kingdom } \\
\hline Number of centers & \multicolumn{2}{|c|}{1} & \multicolumn{3}{|l|}{31} & \multicolumn{2}{|l|}{$51^{\mathrm{a}}$} & \multicolumn{2}{|l|}{56} \\
\hline Setting & \multicolumn{2}{|c|}{ Metropolitan academic teaching hospital } & \multicolumn{3}{|c|}{ Metropolitan academic teaching hospitals } & \multicolumn{2}{|c|}{$\begin{array}{l}\text { Metropolitan and rural tertiary and } \\
\text { non-tertiary care teaching hospitals }\end{array}$} & \multicolumn{2}{|c|}{$\begin{array}{l}\text { National Health Service hospitals } \\
\text { throughout the United Kingdom }\end{array}$} \\
\hline Enrollment time frame & \multicolumn{2}{|c|}{ March 1997-March 2000} & \multicolumn{3}{|c|}{ March 2008-May 2013} & \multicolumn{2}{|c|}{ October 2008-April 2014} & \multicolumn{2}{|c|}{ February 2011-July 2014} \\
\hline Duration of study (months) & \multicolumn{2}{|l|}{36} & \multicolumn{3}{|l|}{62} & \multicolumn{2}{|l|}{66} & \multicolumn{2}{|l|}{41} \\
\hline Patients enrolled & \multicolumn{2}{|l|}{263} & \multicolumn{3}{|l|}{1341} & \multicolumn{2}{|l|}{1600} & \multicolumn{2}{|l|}{1260} \\
\hline Eligible patients excluded & \multicolumn{2}{|l|}{$10.4 \%$} & \multicolumn{3}{|c|}{$65.0 \%$} & \multicolumn{2}{|c|}{$42.7 \%$} & \multicolumn{2}{|c|}{$66.6 \%$} \\
\hline Enrollment/month/center & \multicolumn{2}{|c|}{7} & \multicolumn{3}{|l|}{0.7} & 0.5 & & 0.5 & \\
\hline Lactate screening program & For enre & & Require & & & Requir & & Requir & \\
\hline Existing sepsis protocols & No & & Yes (SS & ndividua & protocols) & Yes (SS & onal standards) & Yes (SS & nal standards) \\
\hline Fluid challenge & $20-30 n$ & & $\begin{array}{l}\text { Initially } \\
\text { (55\% }\end{array}$ & $\begin{array}{l}\mathrm{kg} \text {; cha } \\
\text { using l }\end{array}$ & $\begin{array}{l}1000 \mathrm{~mL} \\
\text { eria) }\end{array}$ & $1000 \mathrm{r}$ & patients) & $1000 n$ & \\
\hline Location of study & ED & & $\mathrm{ED} / \mathrm{ICU}$ & & & $\mathrm{ED} / \mathrm{ICl}$ & & $\mathrm{ED} / \mathrm{ICl}$ & \\
\hline Blinding of ICU clinicians & Yes & & No & & & No & & No & \\
\hline Treatment team structure & ED atte & t, nurses (clinical care) & $\begin{array}{l}\text { Study } \\
\text { coordir }\end{array}$ & nattenc & & $\begin{array}{l}\text { ED or } \\
\text { or nur }\end{array}$ & רsultant, registrar, & $\begin{array}{l}\text { ED or } \\
\text { or nurs }\end{array}$ & sultant, registrar, \\
\hline Hours to randomization & 1.3 & 1.5 & 3.3 & 3.1 & 3.0 & 2.8 & 2.7 & 2.5 & 2.5 \\
\hline ED length of stay (hours) & 8.0 & 6.3 & Not re & & & 1.4 & 2.0 & 1.2 & 1.2 \\
\hline
\end{tabular}

${ }^{a}$ Number of study sites by country-Australia: 42 sites, New Zealand: 3 sites, Finland: 2 sites, Ireland: 1 site and Hong Kong: 3 sites

ARISE Australasian Resuscitation in Sepsis Evaluation, ED emergency department, EGDT Early Goal-Directed Therapy, ICU intensive care unit, MD Medical Doctor, PBST protocol-based standard therapy, ProCESS Protocolized Care for Early Septic Shock, ProMISe Protocolized Management in Sepsis, SSC Surviving Sepsis Campaign 
Table 3 Comparison of enrollment criteria and resuscitation endpoints

\begin{tabular}{|c|c|c|c|c|c|c|c|c|c|}
\hline & & & & ProCESS & & & & & \\
\hline & EGDT & Control & EGDT & PBST & $U C$ & EGDT & Control & EGDT & Control \\
\hline Temperature, ${ }^{\circ} \mathrm{C}$ & 35.9 & 36.6 & 37.6 & 37.6 & 37.7 & 37.6 & 37.6 & & \\
\hline Heart rate, beats/min & 117 & 114 & 113.7 & 114.6 & 114.5 & 104.9 & 104.7 & & \\
\hline Systolic blood pressure, $\mathrm{mm} \mathrm{Hg}$ & 106 & 109 & 100.2 & 102.1 & 99.9 & 78.8 & 79.6 & 77.7 & 78.4 \\
\hline Respiratory rate, breaths/min & 31.8 & 30.2 & 25.4 & 25.1 & 25.3 & 24.5 & 25.1 & & \\
\hline Lactate, $\mathrm{mM} / \mathrm{L}$ & 7.7 & 6.9 & 4.8 & 5.0 & 4.8 & 4.4 & 4.2 & & 5.1 \\
\hline Lactate >4, mM/L (\%) & & & 59 & 59.2 & 60.7 & 46 & 46.5 & 65.4 & 63.7 \\
\hline $\mathrm{CVP}, \mathrm{mmHg}$ & 5.3 & 6.1 & & & & $>10$ & & & \\
\hline $\mathrm{ScvO}_{2}, \%$ & 48.6 & 49.2 & 71 & & & 72.7 & & 70.1 & \\
\hline $\mathrm{pH}$ & 7.31 & 7.32 & 7.33 & 7.31 & 7.34 & & & & \\
\hline $\mathrm{PaCO}_{2}, \mathrm{~mm} \mathrm{Hg}$ & 31.5 & 30.6 & 35.7 & 38.9 & 36.9 & 35.2 & 35.5 & & \\
\hline MAP (6 h), mm Hg & 95 & 81 & 77 & 79 & 76 & 76.5 & 75.3 & 76.5 & 76.5 \\
\hline CVP $(6$ h), mmHg & 13.8 & 11.8 & & & & 11.4 & 11.9 & 11.2 & 11.7 \\
\hline $\mathrm{ScvO}_{2}(6 \mathrm{~h}), \%$ & 77.3 & 66.0 & & & & 75.9 & & 74.2 & \\
\hline
\end{tabular}

Open spaces indicate data not available

ARISE Australasian Resuscitation in Sepsis Evaluation, CVP central venous pressure, EGDT Early Goal-Directed Therapy, MAP mean arterial pressure, $P a C O_{2}$ partial pressure of carbon dioxide, PBST protocol-based standard therapy, ProCESS Protocolized Care for Early Septic Shock, ProMISe Protocolized Management in Sepsis, $\mathrm{SCVO}_{2}$ central venous oxygen saturation, UC usual care

be similarly enrolled in the EGDT trial if they were given $20-30 \mathrm{~mL} / \mathrm{kg}$ of fluids (Tables 4 and 5 ).

\section{Methodology-ED presentation, duration of stay and blinding of care}

Randomization and protocol completion was exclusively performed in the ED (minimum of 7-8 h) in the EGDT trial to reflect the reality of care and maximize external validity [28]. This compares to a length of stay of less than $3 \mathrm{~h}$ in the ED and the remainder in the inpatient setting in the trio of EGDT trials (Table 2). National initiatives to admit patients to the hospital within $4 \mathrm{~h}$ of ED presentation (ProMISe and ARISE) may have improved sepsis care $[34,35]$. It has also been noted in the

Table 4 Comparison of treatments across the EGDT, ProCESS, ARISE, and ProMISe trials

\begin{tabular}{|c|c|c|c|c|c|c|c|c|c|}
\hline & \multicolumn{2}{|c|}{ EGDT } & \multicolumn{3}{|c|}{ ProCESS } & \multicolumn{2}{|c|}{ ARISE } & \multicolumn{2}{|c|}{ ProMISe } \\
\hline & EGDT & Control & EGDT & PBST & UC & EGDT & UC & EGDT & UC \\
\hline Fluid from ED arrival to $6 \mathrm{~h}, \mathrm{~mL}^{\mathrm{a}}$ & 4981 & 3499 & 5059 & 5511 & 4362 & 4479 & 4304 & 4216 & 3987 \\
\hline Fluids $6-72 \mathrm{~h}, \mathrm{~mL}$ & 8625 & 10,602 & 4458 & 4918 & 4354 & 4274 & 4382 & 4215 & 4366 \\
\hline Total fluids 0-72 h, mL & 13,443 & 13,358 & 7253 & 8193 & 6663 & 6906 & 6672 & 5946 & 5844 \\
\hline Vasopressor 0-6 h, \% & 27.4 & 30.3 & 54.9 & 52.2 & 44.1 & 66.6 & 57.8 & 53.3 & 46.6 \\
\hline Vasopressor 6-72 h, \% & 29.1 & 42.9 & 47.6 & 46.6 & 43.2 & 58.8 & 51.5 & 57.9 & 52.6 \\
\hline Vasopressor 0-72 h, \% & 36.8 & 51.3 & 60.4 & 61.2 & 53.7 & & & 60.5 & 55.0 \\
\hline Inotrope $0-6$ h, \% & 13.7 & 0.8 & 8.0 & 1.1 & 0.9 & 15.4 & 2.6 & 18.1 & 3.8 \\
\hline Inotrope 6-72 h, \% & 14.5 & 8.4 & 4.3 & 2.0 & 2.2 & 9.5 & 5.0 & 17.7 & 6.5 \\
\hline Mechanical ventilation 0-6 h, \% & 53.0 & 53.8 & 26.4 & 24.7 & 21.7 & $34.8^{c}$ & $32.9^{c}$ & 20.2 & 19.0 \\
\hline Mechanical ventilation 6-72 h, \% & 2.6 & 16.8 & 33.7 & 31.4 & 27.9 & $38.6^{c}$ & $40.6^{c}$ & 24.4 & 25.4 \\
\hline Any mechanical ventilation, $\%$ & 55.6 & 70.6 & 36.2 & 34.1 & 29.6 & 30.0 & 31.5 & 27.4 & 28.5 \\
\hline Steroids pre-randomization, \% & None & None & 9.3 & 9.4 & 8.3 & & & 5 & 4 \\
\hline Steroids 0-6 h, \% & None & None & 12.3 & 10.8 & 8.1 & & & 11.7 & 11.5 \\
\hline Any steroids 72 h, \% & None & None & & & & 36.9 & 35.9 & 21.9 & 21.1 \\
\hline
\end{tabular}

${ }^{a}$ The Pre-Randomization period refers to a time-frame prior to the time of informed consent for study enrollment. Interventions were initiated as indicated, but these interventions were not considered for outcome evaluations (Additional file 1: Figure S3)

${ }^{\mathrm{b}}$ Combined invasive and non-invasive mechanical ventilation

ARISE Australasian Resuscitation in Sepsis Evaluation, EGDT Early Goal-Directed Therapy, ED emergency department, PBST protocol-based standard therapy,

ProCESS Protocolized Care for Early Septic Shock, ProMISe Protocolized Management in Sepsis, UC usual care 
Table 5 Summary of Methodological Comparisons

\begin{tabular}{|c|c|c|}
\hline & The trio of EGDT trials & EGDT study \\
\hline $\begin{array}{l}\text { Requisite for enrollment and } \\
\text { defined as usual care }\end{array}$ & $\begin{array}{l}\text { Screening using SIRS } \\
\text { Fluid challenge } \\
\text { Lactate screening for cryptic shock } \\
\text { Early antibiotic administration within } 6 \mathrm{~h} \text { encouraged (ProCESS) }\end{array}$ & $\begin{array}{l}\text { No previous standards. Developed from a serie } \\
\text { studies over a decade. }\end{array}$ \\
\hline Enrollment & $\begin{array}{l}\text { Enrollment ( } 8 / \text { site/year) } \\
2 \text { - to } 12-h \text { window of enrollment in the ED } \\
\text { Weekdays and no weekends (ProMISe) } \\
\text { Exclusion rate of } 43 \text { to } 67 \%\end{array}$ & $\begin{array}{l}\text { Single center } \\
1-2 \mathrm{~h} \text { enrollment }\end{array}$ \\
\hline Fluid challenge & Fluid challenge -1 liter or surrogate & $20-30 \mathrm{~mL} / \mathrm{kg}$ \\
\hline Trial duration and timing & $\begin{array}{l}\text { Trials began } 7-8 \text { years after EGDT (2008-2015) } \\
\text { Duration ranging between } 4 \text { and } 8 \text { years } \\
\text { SSC guidelines were published in 2004, 2008, and } 2012\end{array}$ & No existing sepsis protocols \\
\hline Blinding & Open label study in the ICU & ICU was blinded to care provided in the ED \\
\hline Trial conduct & $\begin{array}{l}\text { Duration of ED stay less than } 3 \mathrm{~h} \\
\text { Majority of care provided in ICU } \\
\text { Delayed resuscitation bundle completion after } 6 \mathrm{~h} \text { not tested } \\
\text { High volume and tertiary care centers } \\
\text { CVP placement over } 50 \% \text { of control groups in trio of EGDT trials } \\
\text { A reduction in sample size after interim analysis low mortality }\end{array}$ & $\begin{array}{l}\text { Performed in ED only } \\
6-8 \mathrm{~h} \text { in the ED } \\
\text { Delayed care improves outcomes }\end{array}$ \\
\hline Co-morbidities & $\begin{array}{l}\text { Fewer } \\
\text { Younger patients }\end{array}$ & $\begin{array}{l}\text { Increased cardiovascular, liver, neurologic and } \\
\text { renal failure }\end{array}$ \\
\hline Mechanical ventilation & $\begin{array}{l}\text { Rate of } 26 \% \\
\text { No delayed increase after enrollment } \\
\text { Protective lung strategies }\end{array}$ & $\begin{array}{l}\text { Rate of } 54 \% \\
\text { No protective lung or fluid management } \\
\text { strategies } \\
\text { Increase in delayed MV in the control group. }\end{array}$ \\
\hline Illness severity & $\begin{array}{l}\text { Acute pulmonary edema excluded } \\
\text { Acute lung injury excluded }\end{array}$ & $\begin{array}{l}\text { Lower temperature } \\
\text { Lower } \mathrm{PaCO}_{2} \\
\text { More tachypnea }\end{array}$ \\
\hline Hemodynamic phenotype & $\begin{array}{l}\text { Normal } \mathrm{ScVO}_{2} \text { and } \mathrm{CVP} \text { at baseline (all groups received similar } \\
\text { fluids as the original EGDT treatment group from hospital arrival to } \\
6 \text { hours) } \\
50 \% \text { more vasopressors (vasodilatory) in the trio of EGDT trials } \\
\text { Steroid use } 8-37 \%\end{array}$ & $\begin{array}{l}\text { Lower } \mathrm{ScvO}_{2} \\
\text { Higher lactate } \\
\text { Lower CVP } \\
\text { No steroid use }\end{array}$ \\
\hline Sudden cardiopulmonary & Not a predominant feature & Significant reduction from 20 to $10 \%$ \\
\hline
\end{tabular}

Sources of improved care Pre-existing sepsis protocols, pre-hospital care, sepsis alerts and screens, rapid response systems, telemedicine, glucose control, ventilator strategies, hemoglobin strategies, palliative care, national limits on ED length of stay (Australia and United Kingdom), ultrasound

Generalizability and external Performed in academic centers in industrialized countries validity Specialized care delivery

EGDT replicated in community and academic centers worldwide

CVP central venous pressure, EGDT Early Goal-Directed Therapy, ED emergency department, $I C U$ intensive care unit, $M V$ mechanical ventilation, $P a C O_{2}$ partial pressure of carbon dioxide, ProCESS Protocolized Care for Early Septic Shock, ProMISe Protocolized Management in Sepsis, ScvO ${ }_{2}$ central venous oxygen saturation, SIRS systemic inflammatory response syndrome, SSC Surviving Sepsis Campaign

USA that early ICU admission not only improves the processes of care but contributes to diminishing mortality $[36,37]$.

In the EGDT trial, the admitting inpatient clinicians (ICU) were completely blinded to the randomized treatment group in the ED and clinical variables related to the study during the 72-h follow-up [3, 18]. This included blinding to lactate (and lactate clearance) as well as $\mathrm{ScvO}_{2}$ values over $72 \mathrm{~h}$ as they were not a standard of care and not readily available in the chart. In contrast, the care provided in the trio of EGDT trials was unblinded. The adverse hemodynamic or sudden cardiopulmonary events that occur as a result of the transition and turnover of care from ED to ICU are diminished if care is unblinded and provided by a coordinated research or inpatient team [18].

\section{Antibiotic therapy}

The encouragement or requisite for antibiotic administration prior to enrollment in the trio of EGDT trials is a significant intervention (Additional file 1: Table S4). An $8.5 \%$ increase in mortality for a 6 -h delay or a $7.6 \%$ increase in mortality (septic shock) for each hour of delay from the time of diagnosis to antibiotic therapy has been observed $[38,39]$. The mortality benefit of timely antibiotic 
administration is further enhanced by antibiotic appropriateness [38, 40].

Screening for SIRS criteria, lactate levels, fluid challenge (for hypotension), and antibiotics was a requisite for site enrollment at the centers of the trio of EGDT trials. These interventions can alter the natural trajectory of sepsis progressing to more severe disease, thus mitigating the need for aggressive intervention.

\section{Fluid and vasopressor therapy}

From hospital arrival to the end of the 6-h study period the total fluid volume given ranged from 3.5 to 5.5 liters for the EGDT and trio of trials study groups. Overall, because of the greater lead time prior to enrollment in the trio of EGDT trials, the total volume given was actually similar to the EGDT study treatment group. The comparative differences in fluid therapy were $1482 \mathrm{~mL}$ (42.4\%), $697 \mathrm{~mL}$ (16\%), $175 \mathrm{~mL}$ (4.1\%), and $229 \mathrm{~mL}$ (4.4\%) between the EGDT and usual or control care treatment groups in the EGDT, ProCESS, ARISE, and ProMISe trials, respectively (Table 4 ).

In the EGDT study, the greater volume therapy or treatment effect during the 6 hours of resuscitation was associated with a greater reduction $(13.8 \%)$ in vasopressor therapy, less volume therapy (2 liters or $23 \%$ ) and lower mechanical ventilation rates $(14.2 \%)$ between the EGDT and control group during the subsequent 6- to 72-h time period.

Early and more frequent administration of vasopressors in the trio of EGDT trials may result in a hemodynamic phenotype of "vasodilatory septic shock" which is associated with a lower mortality risk as described by Hernandez et al. [41]. Waechter et al. further report that vasopressor use in the first hour may be associated with increased mortality in patients of greater illness severity [42].

\section{Central venous catheterization}

In the EGDT trial, the timing of central venous catheter (CVC) placement was earlier compared to the trio of EGDT trials because it was an emergent standard of care provided in both treatment groups. As a result, the lower baseline CVP and $\mathrm{ScvO}_{2}$ values in both treatment groups are more consistent with experimental models of sepsis where hypovolemia is predominant (Table 3) [1]. The normal CVP ( $>10 \mathrm{mmHg}$ ) at study entry in the ARISE trial suggests adequate volume resuscitation at enrollment. CVC placement rates were $57.9 \%, 61.9 \%$, and $50.9 \%$ in the control groups of the ProCESS, ARISE, and ProMISe trials, respectively (Additional file 1: Table S2). These CVC placement rates exceed the "real life" CVC placement rate of $35.4 \%$ noted in large observational quality improvement studies where associated mortality reduction is from $47.7 \%$ to $29.5 \%$ (almost identical to the EGDT study) [43]. CVC insertion (within $12 \mathrm{~h}$ of diagnosis) and attainment of the target CVP $\geq 8 \mathrm{~mm} \mathrm{Hg}$ has been associated with lower in-hospital death $[43,44]$. The CVC placement rates in the trio of EGDT trials potentially narrows the treatment effect between the studied groups.

\section{Central venous oxygen saturation $\left(\mathrm{ScvO}_{2}\right)$}

Similar to a low CVP, a low $\mathrm{ScvO}_{2}(<40 \%)$ is a consistent finding in experimental models and observations of early human sepsis $[1,45]$. The lower $\mathrm{ScvO}_{2}$ values in the EGDT trial reflect earlier CVC placement, greater shock severity, or imbalances between $\mathrm{DO}_{2}$ (oxygen delivery) and $\mathrm{VO}_{2}$ (oxygen consumption) before corrective interventions $[26,46,47]$. The frequency of $\mathrm{ScvO}_{2}$ less than $70 \%$ has been reported as $36 \%$ to $45.4 \%$ in ED patients and up to $53 \%$ of ICU admissions. $\mathrm{ScvO}_{2}$ below $70 \%$ upon ICU admission is associated with a $10.4 \%$ increase in hospital mortality [26, 48].

Did the trio of EGDT trials shed light on the role of $\mathrm{ScvO}_{2}$ as an important endpoint of EGDT when the initial mean $\mathrm{ScvO}_{2}$ was $71 \%, 72 \%$, and $70 \%$ in the ProCESS, ARISE, and ProMISe trials, respectively, along with a normal CVP (Table 3)? In the EGDT trial, the mean (and median) $\mathrm{ScvO}_{2}$ of $49 \%$ at randomization was 2 standard deviations below the target $\mathrm{ScvO}_{2}$ of $70 \%$. In other words, $97.5 \%$ of enrolled patients actually required specific steps to normalize $\mathrm{ScvO}_{2}$. Assuming that $\mathrm{ScvO}_{2}$ values were normally distributed-and they were reported and analyzed in the trio of EGDT trials as parametric (normally distributed) data-the median value for $\mathrm{ScvO}_{2}$ would also be greater than or equal to $70 \%$, indicating that half of the patients had a normal baseline $\mathrm{ScvO}_{2}$ or reached the targeted endpoint of EGDT at the time of randomization. Assuming that randomization was effective in the trio of EGDT trials, half of patients in the usual care arms of the studies also would not have "required" specific steps of EGDT to reach this endpoint.

Intention-to-treat (ITT) analysis was a component of the trio of EGDT trials. ITT analysis is limited when the endpoint of the variable in question $\left(\mathrm{ScvO}_{2}\right.$ and $\left.\mathrm{CVP}\right)$ is achieved at the time of randomization [17, 49]. A methodologically more appropriate investigation would randomize patients who required normalization of $\mathrm{ScvO}_{2}$ (or with low baseline $\mathrm{ScvO}_{2}$ ) to receive EGDT versus usual or other forms of care. Unfortunately, without having a CVC inserted, the investigators of the trio of EGDT trials did not have a mechanism for screening those patients with low $\mathrm{ScvO}_{2}$ after meeting the same enrollment criteria as the EGDT trial [17].

\section{Myocardial dysfunction}

Myocardial dysfunction can be present in up to $15 \%$ of septic shock patients, and more frequent in the presence of cardiovascular co-morbidities [50, 51]. In addition, 
greater use of mechanical ventilation can potentiate adverse heart-lung interactions necessitating cardiovascular manipulation (Table 4) [52]. The hemodynamic phenotype of myocardial dysfunction (low $\mathrm{ScvO}_{2}$, increased CVP and lactate) may be absent on physical examination but is associated with increased mortality [53-57]. Inotropic therapy is associated with increased fluid administration as a result of reducing CVP secondary to lowering ventricular end-diastolic pressure (improving compliance) and allowing for fluid administration [58]. Ultrasound assessment has also emerged as a common tool in the ED management of shock. Recent literature suggests that left ventricular strain seen on cardiac ultrasound during sepsis is associated with a decreased $\mathrm{ScvO}_{2}$ and increased lactate [59]. The use of cardiac ultrasound has therefor a potential impact on therapeutic interventions used. The trio of EGDT trials did not formally discuss the use of ultrasound or other technologies (i.e., pulmonary artery catheter) and their treatment effects on usual care.

\section{Mechanical ventilation}

The greater need for mechanical ventilation in the EGDT trial patients compared to the trio of trials is multifactorial and provides unique therapeutic and outcome dimensions (Table 4) [52, 60-62]. At enrollment, there were greater degrees of respiratory demands (increased respiratory rate and decreased partial pressure of carbon dioxide $\left(\mathrm{PaCO}_{2}\right)$ and increasing shock severity (increased lactate and decreased $\mathrm{ScvO}_{2}$ ) in the EGDT trial patients (Table 3). Patients with acute pulmonary edema were excluded from the trio of EGDT trials without specifying a cardiogenic or non-cardiogenic etiology (acute lung injury (ALI)).

Mechanical ventilation alters the hemodynamic phenotype in severe sepsis and septic shock compared to a spontaneously breathing patient $[24,46,60,63]$. While $\mathrm{ScvO}_{2}$ generally increases upon the introduction of mechanical ventilation, hemodynamic perturbations resulting from adverse heart-lung interactions may trigger more therapeutic interventions [63]. These can range from modifying the fraction of inspired oxygen, positive end-expiratory pressure, fluid administration, vasoactive agents, and decreasing the work of breathing after intubation [46, 47, 64]. Normalization of $\mathrm{SvO}_{2}$ even up to $47 \mathrm{~h}$ after disease onset is associated with improved outcomes and decreased duration of mechanical ventilation in the setting of ALI [56]. Decreased duration of mechanical ventilation is associated with more efficient and definitive shock resolution as noted up to $72 \mathrm{~h}$ in the EGDT group of the original trial when compared to the control group $[3,65]$.

The SSC database from 2005 to 2008 reports a mechanical ventilation rate of $52.4 \%$ (7877/15,022 patients) which is almost identical to the EGDT study (Table 4). Mortality rates in this report were 48.3, 45.7, and $33.0 \%$ in mechanically ventilated patients with ALI, without ALI, and without mechanical ventilation, respectively. In a cohort study of the Healthcare Cost and Utilization Project Nationwide Inpatient Sample, Attaway et al. also reported that mortality decreased more in sepsis patients requiring mechanical ventilation $(n=884,848$; from $64.1 \%$ to $39.7 \%$; $p<0.05)$ compared to those that did not require mechanical ventilation $(n=6,963,920 ; 14.8 \%$ to $9.0 \% ; p<0.05)$. They specifically stated that "this occurred over a decade following the introduction of EGDT (2001 to 2012)" [60]. This $24.4 \%$ reduction in mortality is multifactorial, with protective lung strategies accounting for $8.7 \%$ and the remainder attributed to other interventions such as EGDT [61]. The EGDT trial is unique because it was conducted before the introduction of protective lung strategies and alternative fluid management strategies [66, 67].

\section{Corticosteroids}

Adrenal dysfunction has been found to be present in up to $19 \%$ of vasopressor-dependent patients following adequate volume resuscitation in the ED [68]. Over $8 \%$ of all treatment groups in the ProCESS trial received steroids prior to randomization [12]. In the ARISE trial, $36.9 \%$ of the EGDT group versus $35.9 \%$ of the usual care group received steroid therapy within $72 \mathrm{~h}$ due to co-enrollment in a doubleblind randomized trial of corticosteroids in septic shock as noted in the supplemental material of the study [13]. In the ProMISe trial [14], 4-5\% and 11-12\% of both treatment groups received steroids at baseline and within $6 \mathrm{~h}$, respectively (Table 4 ). While the impact of steroids on mortality draws continued debate, recent evidence suggests that early treatment (within $9 \mathrm{~h}$ ) decreases the vasopressor requirement and positively impacts outcome, especially in patients with higher illness severity $[69,70]$. The use of steroids for vasopressor refractory shock was absent in the EGDT trial.

\section{Defining usual care and other influences on mortality}

The trio of EGDT trials was conducted during a period of diminishing sepsis mortality (Table 1) [5, 71, 72]. Quality improvement initiatives and other technologies implemented over this time include pre-hospital management [73], healthcare provider education [74], sepsis and antibiotic administration alerts [75], ultrasound, stroke volume, or pulse pressure variation [76-78], lactate clearance [79], scoring systems [80], rapid response teams [81], telemedicine [82], around the clock intensivist staffing [83], early referral to larger hospitals [20], palliative care [84], state-wide sepsis initiatives [16], improved coding [85], and documentation [86].

As a result of the ubiquitous nature of the SSC over the last decade, sepsis protocols or quality improvement initiatives were evident in a majority of the ProCESS trial sites before or during conduct of the trio of EGDT trials (Additional file 1: Figure S2) $[87,88]$. The Sepsis Six and 
Table 6 Outcomes across the EGDT, ProCESS, and ARISE trials

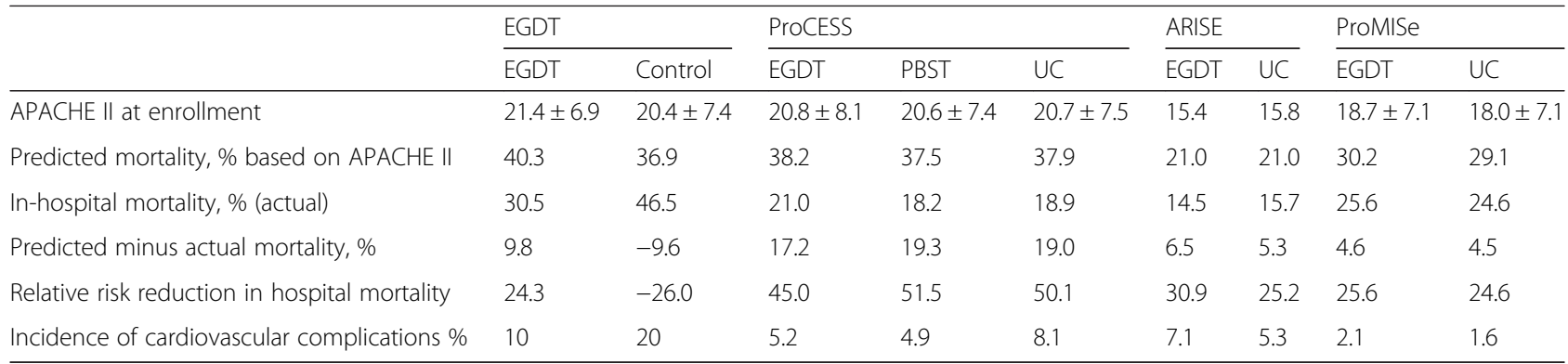

APACHE II Acute Physiology and Chronic Health Evaluation II, ARISE Australasian Resuscitation in Sepsis Evaluation, EGDT Early Goal-Directed Therapy, PBST protocol-based standard therapy, ProCESS Protocolized Care for Early Septic Shock, ProMISe Protocolized Management of Sepsis, UC usual care

SEPSIS KILLS pathway were nationally implemented prior to or paralleling the ProMISe and ARISE trials and have been associated with increased resuscitation bundle compliance and improved mortality $[89,90]$. These generically comprise administering high-flow oxygen, obtaining blood cultures, administering broad spectrum antibiotics and intravenous fluid challenges, and measuring serum lactate and hemoglobin along with accurate hourly urine output. The administration of supplemental oxygen can significantly increase and potentially normalizes $\mathrm{ScvO}_{2}$ even before enrollment $[47,64]$. This is followed by reassessment and early referral to the ICU.

Compliance to the resuscitation bundle elements (lactate, cultures, antibiotics, fluid challenge, and even CVC placement) in the usual care or control groups was over $50 \%$ in each of the trio of EGDT trials. This resulted from CVC placement as a standard of care by usual care or control care clinicians. Large observational studies have shown that even when resuscitation bundle compliance rates improve from $7 \%$ to $29.2 \%$, mortality is reduced from $45.7 \%$ to $29.5 \%$ for an absolute risk reduction of $16.5 \%$ and a relative risk reduction of $36 \%$ $(p<0.001$; Additional File 1: Figure S2) [91].

The trio of EGDT trials did not examine the impact of delayed care. A significant mortality reduction has been observed even with significant delays (up to $12 \mathrm{~h}$ ) before initiating EGDT [92-94]. Patients could potentially receive usual or control arm care during the 6-h study period of the trio of EGDT trials and then receive delayed EGDT or a facsimile, thus altering the treatment effect between groups.

\section{What is the true baseline, control group or usual care mortality?}

Mortality from severe sepsis and septic shock over the decade prior to and paralleling the conduct of the trio of EGDT trials has undergone a consistent and significant decrease (Table 1). For the most common cause of sepsis requiring hospital admission (pneumonia) in the USA, inpatient mortality rates have decreased $45 \%$ among adults between 2002 and 2012 [95]. Whether protocolized care study designs were quasi experimental, prospective observational, prospective with historical controls, or retrospective or randomized controlled, an historical baseline mortality approaches $40-50 \%$ (Table 1). These findings are consistent with a Sepsis International Consensus Definitions Task Force who performed a systematic review comprising 52 studies and 166,479 patients (1993-2015) and reported a septic shock-associated crude mortality of $46.5 \%$ [96]. This reference mortality is identical to the original EGDT trial [3], which supports its external validity

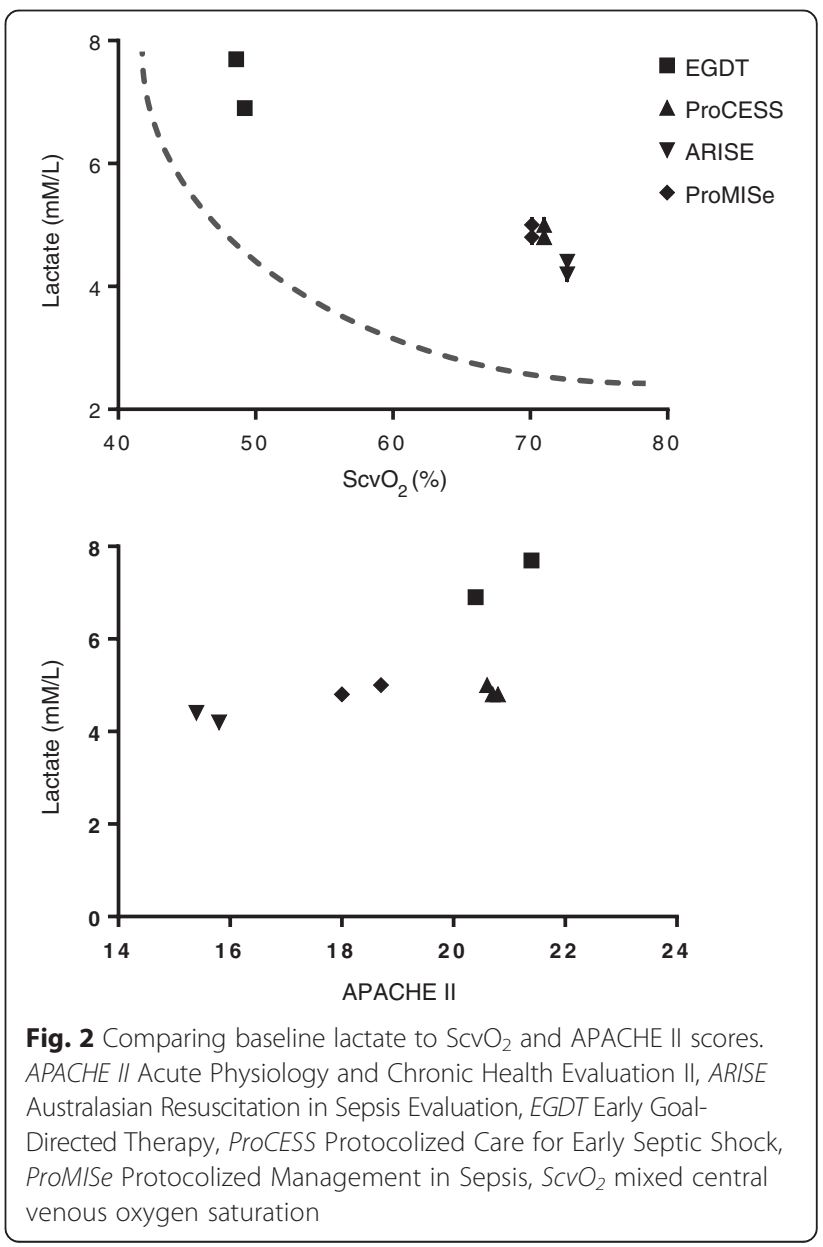


and is nearly twice the mortality of the trio of EGDT trials (Table 1) [12-14]. Using this reference mortality as usual or control group mortality, it is clear that mortality has diminished over the last decade. This significant change in mortality, if not accounted for, increases the likelihood of an underpowered trial [19].

What is the real baseline mortality in the trio of EGDT trials? When the observed hospital mortality is subtracted from the predicted mortality using the baseline mean Acute Physiology and Chronic Health Evaluation (APACHE) II scores, a relative risk mortality reduction of $45-51.5 \%$ in ProCESS, $25.2-30.9 \%$ in ARISE, and $24.6-25.6 \%$ in ProMISe is seen across all treatment groups. These mortality projections similarly compare to the original EGDT trial's relative mortality reduction of $24.3 \%$ between treatment and control groups (Table 6).

\section{Hemodynamic subgroups (phenotypes)}

Early risk stratification of high-risk patients using SIRS, lactate screening, and fluid challenge was a standard of care in all treatment groups in the trio of EGDT trials. Lactate screening not only provides earlier detection of occult shock, but therapeutically alters the natural history of sepsis by decreasing early cardiopulmonary events, which can occur in up to $20 \%$ of patients [3, 97, 98]. These events associated with increased mortality can range from hypotension, respiratory deterioration, and cardiac arrhythmias, to cardiac arrest even after the 6-h trial period and ICU admission [98, 99]. Early lactate screening further leads to a reduction in the time to overall diagnostic results, intravenous fluids, ED care, and ICU admission. The estimated mortality reduction attributed to lactate screening approaches $11 \%$ [100, 101].

In the EGDT trial, the baseline lactate level was almost $2 \mathrm{mM} / \mathrm{L}$ higher than in the trio of EGDT trials. The number of patients with a lactate less than $4 \mathrm{mM} / \mathrm{L}$ was $21 \%$, $45 \%, 54 \%$, and $35.4 \%$ in the EGDT, ProCESS, ARISE, and ProMISe trials, respectively (Table 3) [3, 12-14]. In the ProCESS trial, the number of patients with a lactate greater than $5.3 \mathrm{mM} / \mathrm{L}$ was $12 \%$ higher in the EGDT group compared to the two other study groups $(p=0.05)$.

The combination of a high lactate and low $\mathrm{ScvO}_{2}$ at baseline comprise a hemodynamic phenotype that is independently associated with greater degrees of systemic inflammation, organ dysfunction, and higher mortality [31, 97, 100, 102-105] (Fig. 2). When this hemodynamic phenotype is adjusted for organ dysfunction (lactate/ APACHE II ratio) at baseline, patients in the EGDT trial are also of higher acute illness severity compared to the trio of EGDT trials (Fig. 2) [26, 27, 48, 106].

\section{Conclusions}

EGDT has been shown to have internal and external validity in reducing mortality for the treatment of severe sepsis and septic shock. The various approaches examined by the trio of EGDT trials suggest that alternative strategies can provide an equal reduction in mortality. However, as a result of multiple methodological differences when compared to the original EGDT trial (including undefined usual care), the external validity of these alternative strategies remain to be determined. The combination of a diminishing treatment effect between these alternative strategies and EGDT, along with a global reduction in sepsis mortality over the last 15 years, can render even wellconducted control trials underpowered and inconclusive.

The trio of EGDT trials provides enormous insight into explaining the discrepancy in trials attempting to replicate a previously positive trial over a decade later. It has been shown that large prospective observational studies which have confirmed the external validity and reliability of the EGDT trial provide an equally reliable scientific alternative to randomized control trials $[17-19,107,108]$.

In this era of global reductions in sepsis mortality, clinicians should view EGDT as a verb (series of actions) rather than a noun. Future research should focus on the precision for using invasive or non-invasive approaches at the initial presentation of high risk patients.

\section{Additional file}

Additional file 1: Online Supplemental Information. Figure S1. Oxygen transport and utilization. Figure S2. Changes in mortalities over time in regard to before and after Implementation of EGDT. Figure S3. Pre and Post-Randomization Study Workflow Comparisons. Table S1. Enrollment characteristics and data. Table S2. Comparison of enrollment criteria and resuscitation end-points. Table $\mathbf{S 3}$. Comparison of treatments across the EGDT, ProCESS, ARISE, and ProMISe trials. Table S4. Patient enrollment and treatment initiation. (DOC $543 \mathrm{~kb}$ )

\section{Abbreviations}

ALI: acute lung injury; APACHE: Acute Physiology and Chronic Health Evaluation; ARISE: Australasian Resuscitation in Sepsis Evaluation; CVC: central venous catheter; CVP: central venous pressure; ED: emergency department; EGDT: Early Goal-Directed Therapy; ICU: intensive care unit; ITT: intention-to-treat: ProCESS: Protocol-Based Care for Early Septic Shock; ProMISe: Protocolized Management in Sepsis; $\mathrm{ScvO}_{2}$ : central venous oxygen saturation; SIRS: systemic inflammatory response syndrome; SSC: Surviving Sepsis Campaign; $\mathrm{SVO}_{2}$ : mixed venous oxygen saturation.

\section{Acknowledgement}

We would like to thank Stephanie Stebens, MLIS, AHIP (Librarian, Sladen Library, K-17, Henry Ford Hospital, 2799 West Grand Blvd, Detroit, MI, 48202), for her help with the manuscript.

\section{Funding support}

None

\section{Authors' contributions}

All authors read and approved the final manuscript.

\section{Competing interests}

The authors declare that they have no competing interests. The EGDT study was funded by Henry Ford Hospital Fund for Research. The EGDT study was performed without extramural (academic or industry) funding. All catheters used and equipment in the study were paid for by Henry Ford Hospital to Edwards Lifesciences. Emanuel P. Rivers received no compensation from 
industry during the conduct of the trials and has never received compensation for any intellectual properties related to this study. Steven Q. Simpson has lectured for the Surviving Sepsis Campaign.

\section{Author details}

'Department of Medicine, Pulmonary and Critical Care Medicine, Loma Linda University, Loma Linda, CA, USA. ${ }^{2}$ Department of Emergency Medicine, Loma Linda University, Loma Linda, CA, USA. ${ }^{3}$ Department of Emergency Medicine, Henry Ford Hospital, Wayne State University, Detroit, MI, USA. ${ }^{4}$ Division of Pulmonary and Critical Care Medicine, Mayo Clinic Rochester, Rochester, MN, USA. ${ }^{5}$ Department of Medicine, Pulmonary and Critical Care Medicine, Vanderbilt University, Nashville, TN, USA. ${ }^{6}$ Department of Medicine, Pulmonary and Critical Care Medicine, Henry Ford Hospital, Wayne State University, Detroit, MI, USA. ${ }^{7}$ Department of Medicine, Pulmonary and Critical Care Medicine, University of Kentucky, Lexington, KY, USA. ${ }^{8}$ Department of Internal Medicine, Mercy Hospital Medical Center Chicago, IL, USA. ${ }^{9}$ Department of Internal Medicine, Division of Critical Care Medicine, University of Texas Health Science Center at Houston Houston, TX, USA. ${ }^{10}$ Department of Internal Medicine, Henry Ford Hospital, Wayne State University, Detroit, MI, USA. ${ }^{11}$ CONEVID, Conocimiento y Evidencia Research Unit, Universidad Peruana Cayetano Heredia, Lima, PERU. ${ }^{12}$ Department of Emergency Medicine, Massachusetts General Hospital, Harvard Medical School, Boston, MA, USA. ${ }^{13}$ Pulmonary and Critical Care Medicine, California Pacific Medical Center, San Francisco, CA, USA. ${ }^{14}$ Pulmonary and Critical Care Medicine, University of Kansas, Kansas City, Kansas, USA. ${ }^{15}$ Department of Emergency Medicine, Orlando Regional Medical Center, Orlando, Florida, USA. ${ }^{16}$ University of Central Florida College of Medicine, Orlando, Florida, USA. ${ }^{17}$ University of Florida College of Medicine, Orlando, Florida, USA. ${ }^{18}$ University of South Florida College of Medicine, Orlando, Florida, USA. ${ }^{19}$ Florida State University College of Medicine, Orlando, Florida, USA. ${ }^{20}$ Department of Surgery, Division of Surgical Critical Care, Icahn School of Medicine, Mount Sinai Hospital, New York, NY, USA. ${ }^{21}$ Department of Surgery, Henry Ford Hospital, Wayne State University, Detroit, MI, USA

${ }^{22}$ Department of Quality Assurance, Aspirus Hospital, Iron River, MI, USA.

\section{Published online: 01 July 2016}

\section{References}

1. Rosario AL, Park M, Brunialti MK, Mendes M, Rapozo M, Fernandes D, et al SvO(2)-guided resuscitation for experimental septic shock: effects of fluid infusion and dobutamine on hemodynamics, inflammatory response, and cardiovascular oxidative stress. Shock. 2011;36(6):604-12.

2. Kasnitz P, Druger GL, Yorra F, Simmons DH. Mixed venous oxygen tension and hyperlactatemia. Survival in severe cardiopulmonary disease. JAMA. 1976;236(6):570-4.

3. Rivers E, Nguyen B, Havstad S, Ressler J, Muzzin A, Knoblich B, et al. Early goal-directed therapy in the treatment of severe sepsis and septic shock. N Engl J Med. 2001;345(19):1368-77.

4. Practice parameters for hemodynamic support of sepsis in adult patients in sepsis. Task Force of the American College of Critical Care Medicine, Society of Critical Care Medicine. Crit Care Med. 1999;27(3):639-60.

5. Dellinger RP, Levy MM, Rhodes A, Annane D, Gerlach H, Opal SM, et al. Surviving Sepsis Campaign: international guidelines for management of severe sepsis and septic shock: 2012. Crit Care Med. 2013;41(2):580-637.

6. Lewis RJ. Disassembling goal-directed therapy for sepsis: a first step. JAMA 2010;303(8):777-9.

7. Jones AE. Unbundling early sepsis resuscitation. Ann Emerg Med. 2014;63(6):654-5

8. Gunn SR, Fink MP, Wallace B. Equipment review: the success of early goaldirected therapy for septic shock prompts evaluation of current approaches for monitoring the adequacy of resuscitation. Crit Care. 2005;9(4):349-59.

9. Al-Khafaji A, Rivers E, Shoemaker W. The prospective trial of supranormal values of survivors as therapeutic goals in high-risk surgical patients. Article of Dr. Shoemaker et al with expert commentary by Dr. Emanuel Rivers. 1988. J Crit Care. 2008;23(4):603-6.

10. Bellomo R, Reade MC, Warrillow SJ. The pursuit of a high central venous oxygen saturation in sepsis: growing concerns. Crit Care. 2008;12(2):130

11. Hopkins JA, Shoemaker WC, Chang PC, Schluchter M, Greenfield S. Clinical trial of an emergency resuscitation algorithm. Crit Care Med. 1983;11(8):621-9.
12. Process Investigators, Yealy DM, Kellum JA, Huang DT, Barnato AE, Weissfeld LA, et al. A randomized trial of protocol-based care for early septic shock. N Engl J Med. 2014;370(18):1683-93.

13. ARISE Investigators, Anzics Clinical Trials Group, Peake SL, Delaney A, Bailey M, Bellomo R, Cameron PA, et al. Goal-directed resuscitation for patients with early septic shock. N Engl J Med. 2014;371(16):1496-506.

14. Mouncey PR, Osborn TM, Power GS, Harrison DA, Sadique MZ, Grieve RD, et al. Trial of early, goal-directed resuscitation for septic shock. N Engl J Med. 2015;372(14):1301-11.

15. Angus DC, Barnato AE, Bell D, Bellomo R, Chong CR, Coats TJ, et al. A systematic review and meta-analysis of early goal-directed therapy for septic shock: the ARISE, ProCESS and ProMISe Investigators. Intensive Care Med. 2015;41(9):1549-60.

16. Levy MM. Early goal-directed therapy: what do we do now? Crit Care. 2014;18(6):705

17. Gattinoni L, Giomarelli P. Acquiring knowledge in intensive care: merits and pitfalls of randomized controlled trials. Intensive Care Med. 2015:41(8):1460-4.

18. Vincent JL. We should abandon randomized controlled trials in the intensive care unit. Crit Care Med. 2010;38(10 Suppl):S534-8.

19. Russell JA, Vincent JL. The new trials of early goal-directed resuscitation: three-part harmony or disharmony? Intensive Care Med. 2013;39(10):1867-9.

20. Walkey AJ, Wiener RS. Hospital case volume and outcomes among patients hospitalized with severe sepsis. Am J Respir Crit Care Med. 2014;189(5):548-55.

21. Bell CM, Redelmeier DA. Mortality among patients admitted to hospitals on weekends as compared with weekdays. N Engl J Med. 2001;345(9):663-8.

22. Powell ES, Khare RK, Courtney DM, Feinglass J. The weekend effect for patients with sepsis presenting to the emergency department. J Emerg Med. 2013;45(5):641-8.

23. Kreymann G, Grosser S, Buggisch P, Gottschall C, Matthaei S, Greten H. Oxygen consumption and resting metabolic rate in sepsis, sepsis syndrome, and septic shock. Crit Care Med. 1993;21(7):1012-9.

24. Hussain SN, Simkus G, Roussos C. Respiratory muscle fatigue: a cause of ventilatory failure in septic shock. J Appl Physiol. 1985;58(6):2033-40.

25. Tiruvoipati R, Ong K, Gangopadhyay H, Arora S, Carney I, Botha J. Hypothermia predicts mortality in critically ill elderly patients with sepsis. BMC Geriatr. 2010;10:70.

26. Boulain T, Garot D, Vignon P, Lascarrou JB, Desachy A, Botoc V, et al. Prevalence of low central venous oxygen saturation in the first hours of intensive care unit admission and associated mortality in septic shock patients: a prospective multicentre study. Crit Care. 2014;18(6):609.

27. Wacharasint P, Nakada TA, Boyd JH, Russell JA, Walley KR. Normal-range blood lactate concentration in septic shock is prognostic and predictive. Shock. 2012;38(1):4-10.

28. Liu VX, Morehouse JW, Marelich GP, Soule J, Russell T, Skeath M, et al. Multicenter implementation of a treatment bundle for sepsis patients with intermediate lactate values. Am J Respir Crit Care Med. 2015 [Epub ahead of print].

29. Puskarich MA, Illich BM, Jones AE. Prognosis of emergency department patients with suspected infection and intermediate lactate levels: a systematic review. J Crit Care. 2014;29(3):334-9.

30. Song $Y H$, Shin TG, Kang MJ, Sim MS, Jo IJ, Song KJ, et al. Predicting factors associated with clinical deterioration of sepsis patients with intermediate levels of serum lactate. Shock. 2012;38(3):249-54.

31. Mikkelsen ME, Miltiades AN, Gaieski DF, Goyal M, Fuchs BD, Shah CV, et al. Serum lactate is associated with mortality in severe sepsis independent of organ failure and shock. Crit Care Med. 2009;37(5):1670-7.

32. Lee SJ, Ramar K, Park JG, Gajic O, Li G, Kashyap R. Increased fluid administration in the first three hours of sepsis resuscitation is associated with reduced mortality: a retrospective cohort study. Chest. 2014;146(4):908-15.

33. Jones AE, Yiannibas V, Johnson C, Kline JA. Emergency department hypotension predicts sudden unexpected in-hospital mortality: a prospective cohort study. Chest. 2006;130(4):941-6.

34. Geelhoed GC, de Klerk NH. Emergency department overcrowding, mortality and the 4-hour rule in Western Australia. Med J Aust. 2012;196(2):122-6.

35. Mason S, Weber EJ, Coster J, Freeman J, Locker T. Time patients spend in the emergency department: England's 4-hour rule-a case of hitting the target but missing the point? Ann Emerg Med. 2012;59(5):341-9.

36. Chalfin DB, Trzeciak S, Likourezos A, Baumann BM, Dellinger RP, DELAY-ED study group. Impact of delayed transfer of critically ill patients from the emergency department to the intensive care unit. Crit Care Med. 2007;35(6):1477-83. 
37. Valley TS, Sjoding MW, Ryan AM, Iwashyna TJ, Cooke CR. Association of intensive care unit admission with mortality among older patients with pneumonia. JAMA. 2015;314(12):1272-9.

38. Ferrer R, Martin-Loeches I, Phillips G, Osborn TM, Townsend S, Dellinger RP, et al. Empiric antibiotic treatment reduces mortality in severe sepsis and septic shock from the first hour: results from a guideline-based performance improvement program. Crit Care Med. 2014;42(8):1749-55.

39. Kumar A, Roberts D, Wood KE, Light B, Parrillo JE, Sharma S, et al. Duration of hypotension before initiation of effective antimicrobial therapy is the critical determinant of survival in human septic shock. Crit Care Med. 2006;34(6):1589-96.

40. Kumar A, Ellis P, Arabi Y, Roberts D, Light B, Parrillo JE, et al. Initiation of inappropriate antimicrobial therapy results in a fivefold reduction of survival in human septic shock. Chest. 2009:136(5):1237-48.

41. Hernandez G, Castro R, Romero C, de la Hoz C, Angulo D, Aranguiz I, et al. Persistent sepsis-induced hypotension without hyperlactatemia: is it really septic shock? J Crit Care. 2011;26(4):435. e439-414.

42. Waechter J, Kumar A, Lapinsky SE, Marshall J, Dodek P, Arabi Y, et al. Interaction between fluids and vasoactive agents on mortality in septic shock: a multicenter, observational study. Crit Care Med. 2014;42(10):2158-68.

43. Levy MM, Rhodes A, Phillips GS, Townsend SR, Schorr CA, Beale R, et al. Surviving Sepsis Campaign: association between performance metrics and outcomes in a 7.5-year study. Intensive Care Med. 2014;40(11):1623-33.

44. Walkey AJ, Wiener RS, Lindenauer PK. Utilization patterns and outcomes associated with central venous catheter in septic shock: a population-based study. Crit Care Med. 2013;41(6):1450-7.

45. Astiz ME, Rackow EC, Kaufman B, Falk JL, Weil MH. Relationship of oxygen delivery and mixed venous oxygenation to lactic acidosis in patients with sepsis and acute myocardial infarction. Crit Care Med. 1988;16(7):655-8.

46. Hernandez G, Pena H, Cornejo R, Rovegno M, Retamal J, Navarro JL, et al. Impact of emergency intubation on central venous oxygen saturation in critically ill patients: a multicenter observational study. Crit Care. 2009;13(3):R63.

47. Ho KM, Harding R, Chamberlain J. The impact of arterial oxygen tension on venous oxygen saturation in circulatory failure. Shock. 2008;29(1):3-6.

48. Pope JV, Jones AE, Gaieski DF, Arnold RC, Trzeciak S, Shapiro NI, et al. Multicenter study of central venous oxygen saturation $(\mathrm{ScVO}(2))$ as a predictor of mortality in patients with sepsis. Ann Emerg Med. 2010:55(1):40-6. e41.

49. Gupta SK. Intention-to-treat concept: a review. Perspect Clin Res. 2011;2(3):109-12.

50. Kumar A, Haery C, Parrillo JE. Myocardial dysfunction in septic shock. Crit Care Clin. 2000;16(2):251-87.

51. Ouellette DR, Shah SZ. Comparison of outcomes from sepsis between patients with and without pre-existing left ventricular dysfunction: a case-control analysis. Crit Care. 2014;18(2):R79.

52. de Montmollin E, Aboab J, Ferrer R, Azoulay E, Annane D. Criteria for initiation of invasive ventilation in septic shock: an international survey. J Crit Care. 2016:31(1):54-7.

53. Ander DS, Jaggi M, Rivers E, Rady MY, Levine TB, Levine AB, et al. Undetected cardiogenic shock in patients with congestive heart failure presenting to the emergency department. Am J Cardiol. 1998;82(7):888-91.

54. Perner A, Haase N, Wiis J, White JO, Delaney A. Central venous oxygen saturation for the diagnosis of low cardiac output in septic shock patients. Acta Anaesthesiol Scand. 2010;54(1):98-102.

55. Chamberlain DJ, Willis EM, Bersten AB. The severe sepsis bundles as processes of care: a meta-analysis. Aust Crit Care. 2011;24(4):229-43.

56. Grissom CK, Morris AH, Lanken PN, Ancukiewicz M, Orme Jr JF, Schoenfeld DA, et al. Association of physical examination with pulmonary artery catheter parameters in acute lung injury. Crit Care Med. 2009;37(10):2720-6.

57. Rivers EP, McCord J, Otero R, Jacobsen G, Loomba M. Clinical utility of B-type natriuretic peptide in early severe sepsis and septic shock. J Intensive Care Med. 2007;22(6):363-73.

58. Mark DG, Morehouse JW, Hung YY, Kene MV, Elms AR, Liu V, et al. In-hospital mortality following treatment with red blood cell transfusion or inotropic therapy during early goal-directed therapy for septic shock: a retrospective propensity-adjusted analysis. Crit Care. 2014;18(5):496.

59. Lanspa MJ, Pittman JE, Hirshberg EL, Wilson EL, Olsen T, Brown SM, et al. Association of left ventricular longitudinal strain with central venous oxygen saturation and serum lactate in patients with early severe sepsis and septic shock. Crit Care. 2015;19(1):304

60. Attaway A, Aggarwal A, Noumi B, Velani S, Dasenbrook EC. Comparison of mortality among septic patients requiring endotracheal intubation: cohort study of the Healthcare Cost and Utilization Project's nationwide inpatient sample from 2001-2012. Am J Resp Crit Care Med. 2015;245(191):A1615.
61. Martin-Loeches I, de Haro C, Dellinger RP, Ferrer R, Phillips GS, Levy MM, et al. Effectiveness of an inspiratory pressure-limited approach to mechanical ventilation in septic patients. Eur Respir J. 2013;41(1):157-64.

62. Delbove A, Darreau C, Hamel JF, Asfar P, Lerolle N. Impact of endotracheal intubation on septic shock outcome: a post hoc analysis of the SEPSISPAM trial. J Crit Care. 2015;30(6):1174-8.

63. Krafft P, Steltzer H, Hiesmayr M, Klimscha W, Hammerle AF. Mixed venous oxygen saturation in critically ill septic shock patients. The role of defined events. Chest. 1993;103(3):900-6.

64. Legrand M, Vallee F, Mateo J, Payen D. Influence of arterial dissolved oxygen level on venous oxygen saturation: don't forget the PaO2! Shock. 2014;41(6):510-3.

65. Estenssoro E, Gonzalez F, Laffaire E, Canales H, Saenz G, Reina R, et al. Shock on admission day is the best predictor of prolonged mechanical ventilation in the ICU. Chest. 2005;127(2):598-603.

66. The Acute Respiratory Distress Syndrome Network. Ventilation with lower tidal volumes as compared with traditional tidal volumes for acute lung injury and the acute respiratory distress syndrome. N Engl J Med. 2000;342(18):1301-8.

67. Wiedemann HP, Wheeler AP, Bernard GR, Thompson BT, Hayden D, deBoisblanc $\mathrm{B}$, et al. Comparison of two fluid-management strategies in acute lung injury. N Engl J Med. 2006;354(24):2564-75.

68. Rivers EP, Blake HC, Dereczyk B, Ressler JA, Talos EL, Patel R, et al. Adrenal dysfunction in hemodynamically unstable patients in the emergency department. Acad Emerg Med. 1999;6(6):626-30.

69. Annane D, Bellissant E, Bollaert PE, Briegel J, Confalonieri M, De Gaudio R, et al. Corticosteroids in the treatment of severe sepsis and septic shock in adults: a systematic review. JAMA. 2009;301(22):2362-75.

70. Katsenos CS, Antonopoulou AN, Apostolidou EN, loakeimidou A, Kalpakou GT, Papanikolaou MN, et al. Early administration of hydrocortisone replacement after the advent of septic shock: impact on survival and immune response. Crit Care Med. 2014:42(7):1651-7.

71. Dellinger RP, Carlet JM, Masur H, Gerlach H, Calandra T, Cohen J, et al. Surviving Sepsis Campaign guidelines for management of severe sepsis and septic shock. Crit Care Med. 2004;32(3):858-73.

72. Dellinger RP, Levy MM, Carlet JM, Bion J, Parker MM, Jaeschke R, et al. Surviving Sepsis Campaign: international guidelines for management of severe sepsis and septic shock: 2008. Crit Care Med. 2008;36(1):296-327.

73. Band RA, Gaieski DF, Hylton JH, Shofer FS, Goyal M, Meisel ZF. Arriving by emergency medical services improves time to treatment endpoints for patients with severe sepsis or septic shock. Acad Emerg Med. 2011;18(9):934-40.

74. Capuzzo M, Rambaldi M, Pinelli G, Campesato M, Pigna A, Zanello M, et al Hospital staff education on severe sepsis/septic shock and hospital mortality: an original hypothesis. BMC Anesthesiology. 2012;12:28.

75. Bastani A, Shaqiri B, Mansour S, Anderson W. Sepsis screening clinical decision rule: a novel tool to identify emergency department patients who are at high risk for developing severe sepsis/septic shock. Ann Emerg Med. 2013:62(4):S153-4

76. Stoller $M$, Heller $M$, Krupka $M$, Wang C, Smith $M$, Krieger $P$, et al. Utilizing electronic alerts and IVC ultrasound to improve outcomes for sepsis care in an urban ED. Am J Respir Crit Care Med. 2014;189:A2817.

77. Hirshberg E, Grissom C, Wilson E, Knox D, Brown S, Lanspa M. Decreased left ventricular strain is associated with central venous oxygenation saturation in patients with severe sepsis and septic shock. Am J Respir Crit Care Med. 2014;189:A5499.

78. Rivers EP, Jaehne AK, Eichhorn-Wharry L, Brown S, Amponsah D. Fluid therapy in septic shock. Curr Opin Crit Care. 2010;16(4):297-308.

79. Jones AE, Shapiro NI, Trzeciak S, Arnold RC, Claremont HA, Kline JA, et al. Lactate clearance vs central venous oxygen saturation as goals of early sepsis therapy: a randomized clinical trial. JAMA. 2010;303(8):739-46.

80. Tan D, Xia Z, Zheng A, Zhou C. The value of combination of the mortality in emergency department sepsis score and blood lactate level in the risk stratification of severe sepsis in the emergency department. Zhonghua Wei Zhong Bing Ji Jiu Yi Xue. 2014;26(3):159-64.

81. Khalid I, Qabajah MR, Hamad WJ, Khalid TJ, Digiovine B. Outcome of hypotensive ward patients who re-deteriorate after initial stabilization by the Medical Emergency Team. J Crit Care. 2014;29(1):54-9.

82. Badawi O, Hassan E. Telemedicine and the patient with sepsis. Crit Care Clin. 2015:31(2):291-304

83. Iyegha UP, Asghar Jl, Habermann EB, Broccard A, Weinert C, Beilman G. Intensivists improve outcomes and compliance with process measures in critically ill patients. J Am Coll Surg. 2013;216(3):363-72. 
84. Khandelwal N, Kross EK, Engelberg RA, Coe NB, Long AC, Curtis JR. Estimating the effect of palliative care interventions and advance care planning on ICU utilization: a systematic review. Crit Care Med. 2015:43(5):1102-11.

85. Jafarzadeh SR, Thomas BS, Marschall J, Fraser VJ, Gill J, Warren DK. Quantifying the improvement in sepsis diagnosis, documentation, and coding: the marginal causal effect of year of hospitalization on sepsis diagnosis. Ann Epidemiol. 2016;26(1):66-70.

86. Stoneking LR, Winkler JP, DeLuca LA, Stolz U, Stutz A, Luman JC, et al. Physician documentation of sepsis syndrome is associated with more aggressive treatment. West J Emerg Med. 2015;16(3):401-7.

87. Miller 3rd RR, Dong L, Nelson NC, Brown SM, Kuttler KG, Probst DR, et al. Multicenter implementation of a severe sepsis and septic shock treatment bundle. Am J Respir Crit Care Med. 2013;188(1):77-82.

88. Crowe CA, Mistry CD, Rzechula K, Kulstad CE. Evaluation of a modified early goal-directed therapy protocol. Am J Emerg Med. 2010;28(6):689-93.

89. Robson WP, Daniel R. The Sepsis Six: helping patients to survive sepsis. Br J Nurs. 2008;17(1):16-21.

90. Burrell AR, McLaws ML, Fullick M, Sullivan RB, Sindhusake D. SEPSIS KILLS: early intervention saves lives. Med J Aust. 2016;204(2):73.

91. Rhodes A, Phillips G, Beale R, Cecconi M, Chiche JD, De Backer D, et al. The Surviving Sepsis Campaign bundles and outcome: results from the International Multicentre Prevalence Study on Sepsis (the IMPreSS study). Intensive Care Med. 2015;41(9):1620-8.

92. Castellanos-Ortega A, Suberviola B, Garcia-Astudillo LA, Ortiz F, Llorca J, Delgado-Rodriguez M. Late compliance with the sepsis resuscitation bundle: impact on mortality. Shock. 2011;36(6):542-7.

93. Coba V, Whitmill M, Mooney R, Horst HM, Brandt MM, Digiovine B, et al. Resuscitation bundle compliance in severe sepsis and septic shock: improves survival, is better late than never. J Intensive Care Med. 2011;26(5):304-13.

94. Sohn CH, Ryoo SM, Seo DW, Lee JH, Oh BJ, Lim KS, et al. Outcome of delayed resuscitation bundle achievement in emergency department patients with septic shock. Intern Emerg Med. 2014;9(6):671-6.

95. Hines A, Stranges E, Andrews RM. Trends in Hospital Risk-Adjusted Mortality for Select Diagnoses by Patient Subgroups, 2000-2007. HCUP Statistical Brief \#98. Rockville, MD: Agency for Healthcare Research and Quality; 2010. http://www.hcup-us.ahrq.gov/reports/statbriefs/sb98.pdf. Accessed 4 May 2016.

96. Shankar-Hari M, Phillips GS, Levy ML, Seymour CW, Liu VX, Deutschman CS, et al. Developing a new definition and assessing new clinical criteria for septic shock: for the Third International Consensus Definitions for Sepsis and Septic Shock (Sepsis-3). JAMA. 2016;315(8):775-87.

97. Thomas-Rueddel DO, Poidinger B, Weiss M, Bach F, Dey K, Haberle H, et al. Hyperlactatemia is an independent predictor of mortality and denotes distinct subtypes of severe sepsis and septic shock. J Crit Care. 2015;30(2):439. e431-436

98. Carr GE, Yuen TC, McConville JF, Kress JP, VandenHoek TL, Hall JB, et al. Early cardiac arrest in patients hospitalized with pneumonia: a report from the American Heart Association's Get With The Guidelines-Resuscitation Program. Chest. 2012;141(6):1528-36.

99. Chao PW, Chu H, Chen YT, Shih YN, Kuo SC, Li SY, Ou SM, Shih CJ. Long-term outcomes in critically ill septic patients who survived cardiopulmonary resuscitation. Crit Care Med. 2016, Epub ahead of print

100. Casserly B, Phillips GS, Schorr C, Dellinger RP, Townsend SR, Osborn TM, et al. Lactate measurements in sepsis-induced tissue hypoperfusion: results from the Surviving Sepsis Campaign database. Crit Care Med. 2015;43(3):567-73.

101. Singer AJ, Taylor M, LeBlanc D, Williams J, Thode Jr HC. ED bedside point-of-care lactate in patients with suspected sepsis is associated with reduced time to iv fluids and mortality. Am J Emerg Med. 2014;32(9):1120-4.

102. Puskarich MA, Trzeciak S, Shapiro NI, Heffner AC, Kline JA, Jones AE, et al. Outcomes of patients undergoing early sepsis resuscitation for cryptic shock compared with overt shock. Resuscitation. 2011:82(10):1289-93.

103. Rivers EP, Yataco AC, Jaehne AK, Gill J, Disselkamp M. Oxygen extraction and perfusion markers in severe sepsis and septic shock: diagnostic, therapeutic and outcome implications. Curr Opin Crit Care. 2015;21(5):381-7.

104. Shin TG, Jo IJ, Hwang SY, Jeon K, Suh GY, Choe E, et al. Comprehensive interpretation of central venous oxygen saturation and blood lactate levels during resuscitation of patients with severe sepsis and septic shock in the emergency department. Shock. 2016;45(1):4-9.
105. Rivers EP, Kruse JA, Jacobsen G, Shah K, Loomba M, Otero R, et al. The influence of early hemodynamic optimization on biomarker patterns of severe sepsis and septic shock. Crit Care Med. 2007;35(9):2016-24.

106. Chen YX, Li CS. Arterial lactate improves the prognostic performance of severity score systems in septic patients in the ED. Am J Emerg Med. 2014;32(9):982-6.

107. Benson K, Hartz AJ. A comparison of observational studies and randomized, controlled trials. Am J Ophthalmol. 2000;130(5):688.

108. Concato J, Shah N, Horwitz RI. Randomized, controlled trials, observational studies, and the hierarchy of research designs. N Engl J Med. 2000;342(25):1887-92.

109. Fromm Jr RE, Gibbs LR, McCallum WG, Niziol C, Babcock JC, Gueler AC, et al. Critical care in the emergency department: a time-based study. Crit Care Med. 1993;21(7):970-6

110. Trzeciak S, Rivers EP. Emergency department overcrowding in the United States: an emerging threat to patient safety and public health. Emerg Med J. 2003;20(5):402-5.

111. Nguyen HB, Rivers EP, Havstad S, Knoblich B, Ressler JA, Muzzin AM, et al. Critical care in the emergency department: a physiologic assessment and outcome evaluation. Acad Emerg Med. 2000;7(12):1354-61.

112. Safar P, Benson DM, Esposito G, Grenvik A, Sands PA. Emergency and critical care medicine: local implementation of national recommendations. Clin Anesth. 1974;10(3):65-125.

113. Frank ED. A shock team in a general hospital. Anesth Analg. 1967;46(6):740-5.

114. Rangel-Frausto MS, Pittet D, Costigan M, Hwang T, Davis CS, Wenzel RP. The natural history of the systemic inflammatory response syndrome (SIRS). A prospective study. JAMA. 1995;273(2):117-23.

115. Tuttle A, Nowak R, Grzybowski M, Rivers E, Dereczyk B, Morris D, et al. The systemic inflammatory response syndrome at triage: prevalence and association with hospital admissions. Acad Emerg Med. 1996:3:478.

116. Brun-Buisson C, Doyon F, Carlet J, Dellamonica P, Gouin F, Lepoutre A, et al. Incidence, risk factors, and outcome of severe sepsis and septic shock in adults. A multicenter prospective study in intensive care units. French ICU Group for Severe Sepsis. JAMA. 1995;274(12):968-74.

117. Grzybowski M, Tuttle A, Nowak R, Grzybowski M, Rivers E, Dereczyk B, et al. Systemic inflammatory response syndrome criteria and lactic acidosis in the detection of critical illness among patients presenting to the emergency department. Chest. 1996;110:145S.

118. Weil MH, Afifi AA. Experimental and clinical studies on lactate and pyruvate as indicators of the severity of acute circulatory failure (shock). Circulation. 1970;41(6):989-1001.

119. Aduen J, Bernstein WK, Khastgir T, Miller J, Kerzner R, Bhatiani A, et al. The use and clinical importance of a substrate-specific electrode for rapid determination of blood lactate concentrations. JAMA. 1994;272(21):1678-85.

120. Rady MY, Nightingale P, Little RA, Edwards JD. Shock index: a re-evaluation in acute circulatory failure. Resuscitation. 1992;23(3):227-34.

121. Rady MY, Smithline HA, Blake H, Nowak R, Rivers E. A comparison of the shock index and conventional vital signs to identify acute, critical illness in the emergency department. Ann Emerg Med. 1994:24(4):685-90.

122. Rady M, Rivers EP. The response of blood pressure, heart rate, shock index, central venous oxygen saturataion and lactate to resuscitation in the emergency department. Crit Care Med. 1995;23(1):A138.

123. Natanson C, Danner RL, Reilly JM, Doerfler ML, Hoffman WD, Akin GL, et al. Antibiotics versus cardiovascular support in a canine model of human septic shock. Am J Physiol. 1990;259(5 Pt 2):H1440-7.

124. Natsch S, Kullberg BJ, van der Meer JW, Meis JF. Delay in administering the first dose of antibiotics in patients admitted to hospital with serious infections. Eur J Clin Microbiol Infect Dis. 1998;17(10):681-4.

125. McGarvey RN, Harper JJ. Pneumonia mortality reduction and quality improvement in a community hospital. QRB Qual Rev Bull. 1993;19(4): 124-30.

126. Meakins J, Long CN. Oxygen consumption, oxygen debt and lactic acid in circulatory failure. J Clin Invest. 1927:4(2):273-93.

127. Weil MH, Shubin H, Rosoff L. Fluid repletion in circulatory shock: central venous pressure and other practical guides. JAMA. 1965;192(8):668-74.

128. Wilson JN. Rational approach to management of clinical shock. Arch Surg. 1965;91(1):92.

129. Wilson RF, Wilson JA, Gibson D, Sibbald WJ. Shock in the emergency department. JACEP. 1976:5(9):678-90.

130. Vincent JL, Dufaye P, Berre J, Leeman M, Degaute JP, Kahn RJ. Serial lactate determinations during circulatory shock. Crit Care Med. 1983;11(6):449-51. 
131. Vincent $J$, Gris $P$, Coffernils $M$, Leon M, Pinsky M, Reuse C, et al. Myocardial depression characterizes the fatal course of septic shock. Surgery. 1992; 111(6):660-7.

132. Rivers EP, Ander DS, Powell D. Central venous oxygen saturation monitoring in the critically ill patient. Curr Opin Crit Care. 2001;7(3):204-11.

133. Dombrovskiy VY, Martin AA, Sunderram J, Paz HL. Rapid increase in hospitalization and mortality rates for severe sepsis in the United States: a trend analysis from 1993 to 2003. Crit Care Med. 2007;35(5):1244-50.

134. Ani C, Farshidpanah S, Bellinghausen Stewart A, Nguyen HB. Variations in organism-specific severe sepsis mortality in the United States: 1999-2008. Crit Care Med. 2015;43(1):65-77.

135. Stevenson EK, Rubenstein AR, Radin GT, Wiener RS, Walkey AJ. Two decades of mortality trends among patients with severe sepsis: a comparative meta-analysis. Crit Care Med. 2014;42(3):625-31.

136. Kumar G, Kumar N, Taneja A, Kaleekal T, Tarima S, McGinley E, et al. Nationwide trends of severe sepsis in the 21st century (2000-2007). Chest. 2011;140(5):1223-31.

137. Castellanos-Ortega A, Suberviola B, Garcia-Astudillo LA, Holanda MS, Ortiz F, Llorca J, et al. Impact of the Surviving Sepsis Campaign protocols on hospital length of stay and mortality in septic shock patients: results of a three-year follow-up quasi-experimental study. Crit Care Med. 2010;38(4):1036-43.

138. Laguna-Perez A, Chilet-Rosell E, Delgado Lacosta M, Alvarez-Dardet C, Uris Selles J, Munoz-Mendoza CL. Clinical pathway intervention compliance and effectiveness when used in the treatment of patients with severe sepsis and septic shock at an intensive care unit in Spain. Rev Lat Am Enfermagem. 2012;20(4):635-43.

139. Memon Jl, Rehmani RS, Alaithan AM, El Gammal A, Lone TM, Ghorab K, et al. Impact of 6-hour sepsis resuscitation bundle compliance on hospital mortality in a Saudi hospital. Crit Care Res Pract. 2012;2012:273268.

140. Shiramizo SC, Marra AR, Durao MS, Paes AT, Edmond MB. Pavao dos Santos OF. Decreasing mortality in severe sepsis and septic shock patients by implementing a sepsis bundle in a hospital setting. PLoS One. 2011;6(11):e26790.

141. Apibunyopas Y. Mortality rate among patients with septic shock after implementation of 6-hour sepsis protocol in the emergency department of Thammasat University Hospital. Journal Med Ass Thai. 2014;97 Suppl 8: S182-93.

142. Cannon CM, Holthaus CV, Zubrow MT, Posa P, Gunaga S, Kella V, et al. The GENESIS project (GENeralized Early Sepsis Intervention Strategies): a multicenter quality improvement collaborative. J Intensive Care Med. 2013; 28(6):355-68.

143. Cardoso T, Carneiro AH, Ribeiro O, Teixeira-Pinto A, Costa-Pereira A. Reducing mortality in severe sepsis with the implementation of a core 6-hour bundle: results from the Portuguese community-acquired sepsis study (SACiUCI study). Crit Care. 2010;14(3):R83.

144. Casserly B, Baram M, Walsh P, Sucov A, Ward NS, Levy MM. Implementing a collaborative protocol in a sepsis intervention program: lessons learned. Lung. 2011;189(1):11-9.

145. Crowe CA, Kulstad EB, Mistry CD, Kulstad CE. Comparison of severity of illness scoring systems in the prediction of hospital mortality in severe sepsis and septic shock. J Emerg Trauma Shock. 2010;3(4):342-7.

146. Ferrer R, Artigas A, Levy MM, Blanco J, Gonzalez-Diaz G, Garnacho-Montero J, et al. Improvement in process of care and outcome after a multicenter severe sepsis educational program in Spain. JAMA. 2008;299(19):2294-303.

147. Focht $A$, Jones $A E$, Lowe TJ. Early goal-directed therapy: improving mortality and morbidity of sepsis in the emergency department. Jt Comm J Qual Patient Saf. 2009;35(4):186-91

148. Gao F, Melody T, Daniels DF, Giles S, Fox S. The impact of compliance with 6hour and 24-hour sepsis bundles on hospital mortality in patients with severe sepsis: a prospective observational study. Crit Care. 2005;9(6):R764-770.

149. Gatewood MO, Wemple M, Greco S, Kritek PA, Durvasula R. A quality improvement project to improve early sepsis care in the emergency department. BMJ Qual Saf. 2015:24(12):787-95.

150. Girardis M, Rinaldi L, Donno L, Marietta M, Codeluppi M, Marchegiano P, et al. Effects on management and outcome of severe sepsis and septic shock patients admitted to the intensive care unit after implementation of a sepsis program: a pilot study. Crit Care. 2009;13(5):R143.

151. Guerra WF, Mayfield TR, Meyers MS, Clouatre AE, Riccio JC. Early detection and treatment of patients with severe sepsis by prehospital personnel. J Emerg Med. 2013;44(6):1116-25.
152. Guo Q, Li HY, Li YM, Nong LB, Xu YD, He GQ, et al. Compliance with severe sepsis bundles and its effect on patient outcomes of severe community-acquired pneumonia in a limited resources country. Arch Med Sci. 2014;10(5):970-8.

153. Gurnani PK, Patel GP, Crank CW, Vais D, Lateef O, Akimov S, et al. Impact of the implementation of a sepsis protocol for the management of fluidrefractory septic shock: a single-center, before-and-after study. Clin Ther. 2010;32(7):1285-93.

154. Jacob ST, Banura P, Baeten JM, Moore CC, Meya D, Nakiyingi L, et al. The impact of early monitored management on survival in hospitalized adult Ugandan patients with severe sepsis: a prospective intervention study. Crit Care Med. 2012;40(7):2050-8.

155. Jones AE, Focht A, Horton JM, Kline JA. Prospective external validation of the clinical effectiveness of an emergency department-based early goal-directed therapy protocol for severe sepsis and septic shock. Chest. 2007;132(2):425-32.

156. Jones AE, Troyer JL, Kline JA. Cost-effectiveness of an emergency department-based early sepsis resuscitation protocol. Crit Care Med. 2011; 39(6):1306-12.

157. Kliger J, Singer SJ, Hoffman FH. Using the integrated nurse leadership program to reduce sepsis mortality. Jt Comm J Qual Patient Saf. 2015;41(6):264-72.

158. Kuan WS, Mahadevan M, Tan JH, Guo J, Ibrahim I. Feasibility of introduction and implementation of the Surviving Sepsis Campaign bundle in a Singapore emergency department. Eur J Emerg Med. 2013;20(5):344-9.

159. Micek ST, Roubinian N, Heuring T, Bode M, Williams J, Harrison C, et al. Before-after study of a standardized hospital order set for the management of septic shock. Crit Care Med. 2006;34(11):2707-13.

160. Na S, Kuan WS, Mahadevan M, Li CH, Shrikhande P, Ray S, et al. Implementation of early goal-directed therapy and the surviving sepsis campaign resuscitation bundle in Asia. Int J Qual Health Care. 2012;24(5):452-62.

161. Nguyen HB, Corbett SW, Steele R, Banta J, Clark RT, Hayes SR, et al. Implementation of a bundle of quality indicators for the early management of severe sepsis and septic shock is associated with decreased mortality. Crit Care Med. 2007;35(4):1105-12.

162. Noritomi DT, Ranzani OT, Monteiro MB, Ferreira EM, Santos SR, Leibel F, et al. Implementation of a multifaceted sepsis education program in an emerging country setting: clinical outcomes and cost-effectiveness in a long-term follow-up study. Intensive Care Med. 2014;40(2):182-91.

163. Qu HP, Qin S, Min D, Tang YQ. The effects of earlier resuscitation on following therapeutic response in sepsis with hypoperfusion. Zhonghua Wai Ke Za Zhi. 2006:44(17):1193-6.

164. Rinaldi L, Ferrari E, Marietta M, Donno L, Trevisan D, Codeluppi M, et al. Effectiveness of sepsis bundle application in cirrhotic patients with septic shock: a single-center experience. J Crit Care. 2013;28(2):152-7.

165. Salleh FM, Fathil SM, Zulkernain A, Zuraidah CM. Early goal-directed therapy in the management of severe sepsis/septic shock in an academic emergency department in Malaysia. Crit Care Shock. 2010;13(3):91-7.

166. Schramm GE, Kashyap R, Mullon JJ, Gajic O, Afessa B. Septic shock: a multidisciplinary response team and weekly feedback to clinicians improve the process of care and mortality. Crit Care Med. 2011;39(2):252-8.

167. Siontis B, Elmer J, Dannielson R, Brown C, Park J, Surani S, et al. Multifaceted interventions to decrease mortality in patients with severe sepsis/septic shock-a quality improvement project. Peer J. 2015:3:e1290.

168. van Zanten AR, Brinkman S, Arbous MS, Abu-Hanna A, Levy MM, de Keizer $N F$, et al. Guideline bundles adherence and mortality in severe sepsis and septic shock. Crit Care Med. 2014;42(8):1890-8.

169. Wang Z, Xiong Y, Schorr C, Dellinger RP. Impact of sepsis bundle strategy on outcomes of patients suffering from severe sepsis and septic shock in china. J Emerg Med. 2013;44(4):735-41.

170. Westphal GA, Koenig A, Caldeira Filho M, Feijo J, de Oliveira LT, Nunes F, et al. Reduced mortality after the implementation of a protocol for the early detection of severe sepsis. J Crit Care. 2011;26(1):76-81.

171. Winterbottom F, Seoane L, Sundell E, Niazi J, Nash T. Improving sepsis outcomes for acutely ill adults using interdisciplinary order sets. Clin Nurse Spec. 2011;25(4):180-5

172. Yang M, Graham C, Rainer T. Outcome after implementation of sepsis guideline in the emergency department of a university hospital in Hong Kong. Hong Kong J Emerg Med. 2015:22(3):163-71.

173. Zambon M, Ceola M, Almeida-de-Castro R, Gullo A, Vincent JL. Implementation of the Surviving Sepsis Campaign guidelines for severe sepsis and septic shock: we could go faster. J Crit Care. 2008;23(4):455-60. 
174. Herrán-Monge R, Muriel-Bombín A, García-García MM, Merino-García PA, Cítores-González R, Fernández-Ratero JA, Albalá N, Carriedo D, MoradilloGonzález S, Álvarez-Martínez B, et al. Mortality reduction and long-term compliance with Surviving Sepsis Campaign. Shock. 2015, Published ahead of print.

175. Assuncao MS, Teich V, Shiramizo SC, Araujo DV, Carrera RM, Serpa Neto A, et al. The cost-effectiveness ratio of a managed protocol for severe sepsis. J Crit Care. 2014;29(4):692. e691-696.

176. El Solh AA, Akinnusi ME, Alsawalha LN, Pineda LA. Outcome of septic shock in older adults after implementation of the sepsis "bundle". J Am Geriatr Soc. 2008:56(2):272-8.

177. Lefrant JY, Muller L, Raillard A, Jung B, Beaudroit L, Favier L, et al. Reduction of the severe sepsis or septic shock associated mortality by reinforcement of the recommendations bundle: a multicenter study. Ann Fr Anesth Reanim. 2010;29(9):621-8.

178 MacRedmond R, Hollohan K, Stenstrom R, Nebre R, Jaswal D, Dodek P. Introduction of a comprehensive management protocol for severe sepsis is associated with sustained improvements in timeliness of care and survival. Qual Saf Health Care. 2010;19(5):e46.

179. Patel GW, Roderman N, Gehring H, Saad J, Bartek W. Assessing the effect of the Surviving Sepsis Campaign treatment guidelines on clinical outcomes in a community hospital. Ann Pharmacother. 2010;44(11):1733-8.

180. Puskarich MA, Marchick MR, Kline JA, Steuerwald MT, Jones AE. One year mortality of patients treated with an emergency department based early goal directed therapy protocol for severe sepsis and septic shock: a before and after study. Crit Care. 2009;13(5):R167.

181. Ryoo SM, Kim WY, Sohn CH, Seo DW, Koh JW, Oh BJ, et al. Prognostic value of timing of antibiotic administration in patients with septic shock treated with early quantitative resuscitation. Am J Med Sci. 2015;349(4):328-33.

182. Sebat F, Johnson D, Musthafa AA, Watnik M, Moore S, Henry K, et al. A multidisciplinary community hospital program for early and rapid resuscitation of shock in nontrauma patients. Chest. 2005;127(5):1729-43.

183. Shapiro NI, Howell MD, Talmor D, Lahey D, Ngo L, Buras J, et al. Implementation and outcomes of the Multiple Urgent Sepsis Therapies (MUST) protocol. Crit Care Med. 2006;34(4):1025-32.

184. Hanzelka KM, Yeung SC, Chisholm G, Merriman KW, Gaeta S, Malik I, et al. Implementation of modified early-goal directed therapy for sepsis in the emergency center of a comprehensive cancer center. Support Care Cancer. 2013;21(3):727-34

185. Jeon K, Shin TG, Sim MS, Suh GY, Lim SY, Song HG, et al. Improvements in compliance with resuscitation bundles and achievement of end points after an educational program on the management of severe sepsis and septic shock. Shock. 2012;37(5):463-7.

186. Kang MJ, Shin TG, Jo IJ, Jeon K, Suh GY, Sim MS, et al. Factors influencing compliance with early resuscitation bundle in the management of severe sepsis and septic shock. Shock. 2012;38(5):474-9.

187. Kortgen A, Niederprum P, Bauer M. Implementation of an evidence-based "standard operating procedure" and outcome in septic shock. Crit Care Med. 2006:34(4):943-9.

188. Mikkelsen ME, Gaieski DF, Goyal M, Miltiades AN, Munson JC, Pines JM, et al Factors associated with nonadherence to early goal-directed therapy in the ED. Chest. 2010;138(3):551-8.

189. Sivayoham N, Rhodes A, Jaiganesh T, van Zyl SN, Elkhodhair S, Krishnanandan S. Outcomes from implementing early goal-directed therapy for severe sepsis and septic shock : a 4-year observational cohort study. Eur J Emerg Med. 2012;19(4):235-40.

190. Thiel SW, Asghar MF, Micek ST, Reichley RM, Doherty JA, Kollef MH. Hospital-wide impact of a standardized order set for the management of bacteremic severe sepsis. Crit Care Med. 2009:37(3):819-24.

191. Tromp M, Bleeker-Rovers CP, van Achterberg T, Kullberg BJ, Hulscher M, Pickkers P. Internal medicine residents' knowledge about sepsis: effects of a teaching intervention. Neth J Med. 2009;67(9):312-5.

192. Trzeciak S, Dellinger RP, Abate NL, Cowan RM, Stauss M, Kilgannon JH, et al. Translating research to clinical practice: a 1-year experience with implementing early goal-directed therapy for septic shock in the emergency department. Chest. 2006;129(2):225-32.

193. Wawrzeniak I, Loss S, Moraes M, De La Vega F, Victorino J. Could a protocol based on early goal-directed therapy improve outcomes in patients with severe sepsis and septic shock in the intensive care unit setting? Indian J Crit Care Med. 2015:19(3):159-65.
194. Early Goal-Directed Therapy Collaborative Group of Zhejiang P. The effect of early goal-directed therapy on treatment of critical patients with severe sepsis/septic shock: a multi-center, prospective, randomized, controlled study. Zhongguo Wei Zhong Bing Ji Jiu Yi Xue. 2010;22(6):331-4.

195. Chen ZQ, Jin YH, Chen H, Fu WJ, Yang H, Wang RT. Early goal-directed therapy lowers the incidence, severity and mortality of multiple organ dysfunction syndrome. Nan Fang Yi Ke Da Xue Xue Bao. 2007;27(12):1892-5.

196. He ZY, Gao Y, Wang XR, Hang YN. Clinical evaluation of execution of early goal directed therapy in septic shock. Zhongguo Wei Zhong Bing Ji Jiu Yi Xue. 2007;19(1):14-6.

197. Lin SM, Huang CD, Lin HC, Liu CY, Wang CH, Kuo HP. A modified goaldirected protocol improves clinical outcomes in intensive care unit patients with septic shock: a randomized controlled trial. Shock. 2006;26(6):551-7.

198. Wang XZ, Lu CJ, Gao FQ, Li XH, Yan WF, Ning FY. Efficacy of goal-directed therapy in the treatment of septic shock. Zhongguo Wei Zhong Bing Ji Jiu Yi Xue. 2006;18(11):661-4.

199. Yan J, Cai G. A multicentre study on early goal-directed therapy of severe sepsis and septic shock patients in the ICU: collaborative study group on early goaldirected therapy in Zhejiang Province, China. Crit Care. 2008;12 Suppl 2:417.

200. Padkin A, Goldfrad C, Brady AR, Young D, Black N, Rowan K. Epidemiology of severe sepsis occurring in the first 24 hrs in intensive care units in England, Wales, and Northern Ireland. Crit Care Med. 2003:31(9):2332-8.

201. Reuben AD, Appelboam AV, Higginson I. The outcomes of severe sepsis and septic shock in the UK. Crit Care. 2006;10(4):417.

202. Melville J, Ranjan S, Morgan P. ICU mortality rates in patients with sepsis before and after the Surviving Sepsis Campaign. Crit Care. 2015;19 Suppl 1:15-P15.

203. Daniels R, Nutbeam T, McNamara G, Galvin C. The sepsis six and the severe sepsis resuscitation bundle: a prospective observational cohort study. Emerg Med J. 2011;28(6):507-12.

204. Finfer S, Bellomo R, Lipman J, French C, Dobb G, Myburgh J. Adult-population incidence of severe sepsis in Australian and New Zealand intensive care units. Intensive Care Med. 2004;30(4):589-96.

205. Kaukonen KM, Bailey M, Suzuki S, Pilcher D, Bellomo R. Mortality related to severe sepsis and septic shock among critically ill patients in Australia and New Zealand, 2000-2012. JAMA. 2014;311(13):1308-16. 